\title{
UK guidelines for the management of bone sarcomas
}

\author{
Craig Gerrand ${ }^{1 *}$, Nick Athanasou ${ }^{2}$, Bernadette Brennan ${ }^{3}$, Robert Grimer ${ }^{4}$, lan Judson 5 , Bruce Morland ${ }^{6}$, \\ David Peake ${ }^{7}$, Beatrice Seddon ${ }^{8}$, Jeremy Whelan ${ }^{8}$ and On behalf of the British Sarcoma Group
}

\begin{abstract}
This document is an update of the British Sarcoma Group guidelines published in 2010. The aim is to provide a reference standard for the clinical care of patients in the UK with bone sarcomas. Recent recommendations by the European Society of Medical Oncology, The National Comprehensive Cancer Network and The National Institute for Health and Care Excellence have been incorporated, and the literature since 2010 reviewed. The standards represent a consensus amongst British Sarcoma Group members in 2015. It is acknowledged that these guidelines will need further updates as care evolves. The key recommendations are that bone pain or a palpable mass should always lead to further investigation and that patients with clinico-radiological findings suggestive of a primary bone tumour at any site in the skeleton should be referred to a specialist centre and managed by a fully accredited bone sarcoma multidisciplinary team. Treatment recommendations are provided for the major tumour types and for localised, metastatic and recurrent disease. Follow up schedules are suggested.
\end{abstract}

\section{Background}

\section{Rationale and objective of guidelines}

Bone sarcomas are uncommon malignancies and it was recognised more than 30 years ago that their management should be centralized. Following various NHS reforms, the diagnosis and surgical treatment of primary bone sarcomas is now commissioned by the NHS England Highly Specialized Commissioning Group [1] in five centres in England. However, other treatments such as chemotherapy and radiotherapy may be delegated to other centres. Arrangements in Scotland and Northern Ireland differ. The surgical treatment of patients in Wales takes place in specialist centres in England, with other modalities of treatment delivered within Wales.

This reference document aims to improve the quality of care for patients with bone tumours by identifying and informing key management decisions and is an update of the 2010 British Sarcoma Group (BSG) guidelines [2].

\footnotetext{
${ }^{*}$ Correspondence: Craig.Gerrand@nuth.nhs.uk

${ }^{1}$ Newcastle upon Tyne Hospitals NHS Foundation Trust, Freeman Hospital, Newcastle upon Tyne NE7 7DN, UK

Full list of author information is available at the end of the article
}

\section{Methods}

In developing these guidelines, the following were consulted: The National Comprehensive Cancer Network (NCCN) Clinical Practice Guidelines [3]; ESMO/European Network Working Group, Clinical Practice Guidelines for Bone Sarcomas [4]; National Institute for Health and Care Excellence (NICE) Quality Standard [QS78] Sarcoma [5] and Suspected cancer: recognition and referral guideline [NG12] [6] and the published literature from 2010 to 2015 . The authors considered the applicability to UK practice and reached consensus on the content. The document was then circulated widely within the British Sarcoma Group for comment and approval.

\section{Scope of guidelines}

The guidelines apply to all primary bone sarcomas (and giant cell tumours of bone) arising in any skeletal location. These guidelines consider clinical effectiveness, and include treatments to which a specialist bone sarcoma multidisciplinary team (MDT) in the UK should have access. While representing a broad consensus in 2015 , these guidelines will require updating as treatment evolves. Haemopoietic tumours of bone, rehabilitation, prosthetic services and palliative care are not included. 


\section{Classification of bone sarcomas}

Primary malignant bone tumours comprise $0.2 \%$ of all cancers diagnosed in England and have an annual incidence of around 7.9 per million [7]. On average, 380 people were diagnosed with primary bone sarcomas each year in England between 1985 and 2009. Therefore, a General Practitioner (GP) is unlikely to see a patient with a bone sarcoma in a working lifetime. Delays in diagnosis are common. Reducing delays would almost certainly lead to improved survival outcomes and less extensive surgery [8].

Despite their rarity, primary malignant bone tumours comprise approximately $5 \%$ of all childhood cancers in European Countries [7, 9] and include two major cancers of children and young adults: osteosarcoma and Ewing sarcoma [7]. In children under 5 years of age, a destructive bone lesion is more likely to be metastatic neuroblastoma or eosinophilic granuloma $[4,10]$. Chondrosarcoma is more common in middle aged and elderly people [7].

In adults, especially those over 40 years of age, metastatic carcinomas (usually from lung, breast, thyroid, kidney or prostate) and haemopoietic malignancies (e.g. plasma cell tumour or lymphoma) in bone considerably outnumber primary bone tumours. At any age the possibility of a benign lesion or infection must be considered [11]. If there is diagnostic uncertainty, it should be assumed the patient has a primary bone sarcoma until proven otherwise [12].

There has been no significant improvement in 5-year overall survival rates for patients with bone sarcomas over the past $25-30$ years, with rates static at between 53 and $55 \%[7,13]$.

A classification of bone sarcomas adapted from the World Health Organization (WHO) classification of primary bone tumours is shown in Table 1 [14].

Although some inherited and acquired factors are associated with the development of primary bone tumours, a cause cannot be identified in the majority of patients [ 15 , $16]$.

The 5-year relative survival for patients diagnosed in England in 1985-2004 is considerably lower than that reported within the US Surveillance, Epidemiology and End Results (SEER) programme (66 \%) [17]. This may reflect the fact that patients in the SEER programme are younger $(30 \%$ of NCIN patients were $>65$ years, compared with $21 \%$ of SEER patients: $22 \%$ of NCIN patients were $<19$ years, compared with $29 \%$ of SEER patients). Furthermore, the SEER programme does not specify which morphological sub-types are included. Further investigation is required [7].

\section{Osteosarcoma}

Osteosarcoma is the second most frequent primary cancer of bone and accounts for over $10 \%$ of all solid cancers
Table 1 Classification of malignant primary bone tumours (adapted from WHO classification [14])

\begin{tabular}{|c|c|}
\hline Chondrogenic tumours & $\begin{array}{l}\text { (1) Atypical cartilaginous tumour/ } \\
\text { chondrosarcoma (grade I) } \\
\text { (2) Chondrosarcoma (grades II/III) } \\
\text { (3) Dedifferentiated chondrosarcoma } \\
\text { (4) Mesenchymal chondrosarcoma } \\
\text { (5) Clear cell chondrosarcoma }\end{array}$ \\
\hline Osteogenic tumours & $\begin{array}{l}\text { (1) Low-grade central osteosarcoma } \\
\text { (2) Conventional (high-grade) osteosarcoma } \\
\text { (chondroblastic fibroblastic osteoblastic) } \\
\text { (3) Telangiectatic osteosarcoma } \\
\text { (4) Small cell osteosarcoma } \\
\text { (5) Secondary osteosarcoma } \\
\text { (6) Parosteal osteosarcoma } \\
\text { (7) Periosteal osteosarcoma } \\
\text { (8) High-grade surface osteosarcoma }\end{array}$ \\
\hline Notochordal tumours & Chordoma \\
\hline Vascular tumours & $\begin{array}{l}\text { (1) Epithelioid haemangioendothelioma } \\
\text { (2) Angiosarcoma }\end{array}$ \\
\hline $\begin{array}{l}\text { Other malignant } \\
\text { mesenchymal tumours }\end{array}$ & $\begin{array}{l}\text { Fibrosarcoma, Leiomyosarcoma, } \\
\text { Liposarcoma etc. }\end{array}$ \\
\hline Miscellaneous tumours & $\begin{array}{l}\text { (1) Ewing sarcoma } \\
\text { (2) Adamantinoma } \\
\text { (3) Undifferentiated high-grade pleomorphic } \\
\text { sarcoma of bone }\end{array}$ \\
\hline
\end{tabular}

in adolescents (age 15-19). Another peak in incidence occurs in the seventh and eighth decades of life $[7,13]$. It is slightly more common in males (male to female ratio 1.4:1.0) [7]. Survival rates are significantly higher in younger patients (5-year survival, $<40$ years $53 \%$ vs. $>40$ years $22 \%$; $\mathrm{p}<0.0001)[7,13]$.

Osteosarcoma usually arises in the metaphysis of an extremity long bone, most commonly around the knee $[18,19]$. Some tumours (predominantly in adults) arise in the axial skeleton, pelvis or craniofacial bones. Risk factors for osteosarcoma include previous radiation therapy, Paget's disease of bone and germline abnormalities such as Li-Fraumeni syndrome, Werner syndrome, Rothmund -Thomson syndrome and familial retinoblastoma [20, 21]. The temporal association of osteosarcoma with the pubertal growth spurt and the location in the metaphysis of long bones suggest an association with rapid bone growth.

\section{Ewing sarcoma}

Ewing sarcoma is the second most common primary malignant bone tumour in children and adolescents, but is also seen in adults. The median age at diagnosis is around 15 years and in the UK there is a male preponderance of 1.5:1 [7]. It is less common in people of Chinese or Black African origin. Identification of chromosomal translocations specific to Ewing sarcoma e.g. (t11;22) have provided a useful diagnostic criterion. In recent years undifferentiated bone sarcomas with morphological 
features of Ewing sarcoma but with uncharacteristic translocations e.g. CIC-DUX have been described. Although clinical information is limited these appear to respond less well than Ewing sarcoma to chemotherapy and may have an unfavourable prognosis [22].

The most frequent anatomical sites of involvement of Ewing sarcoma are the long bones, pelvis, ribs and vertebral column. All forms of Ewing Sarcoma are high grade $[23,24]$.

\section{Chondrosarcoma}

Chondrosarcoma most commonly presents between 30 and 60 years of age [7]. The ageing UK population means that chondrosarcoma has become the most common bone sarcoma, ahead of osteosarcoma [25]. Differentiating between an atypical enchondroma and a low grade chondrosarcoma can be extremely difficult and has led to these tumours being categorised together in the WHO classification as atypical cartilaginous tumour/chondrosarcoma grade I. It is considered to be a tumour of intermediate malignancy, most often behaving in a locally aggressive fashion and rarely metastasising. Care must be taken not to overtreat benign tumours or undertreat malignant ones [26].

Most chondrosarcomas are located in long bones but they also arise in flat bones (e.g. pelvis, rib and scapula). Chondrosarcomas arising in pre-existing benign lesions such as osteochondromas and enchondromas are known as secondary peripheral chondrosarcomas and secondary central chondrosarcomas respectively. The risk of developing chondosarcoma in solitary osteochondromas and enchondromas is uncertain, but is increased when there are multiple lesions or when lesions are located in the axial skeleton, particularly the pelvis [27].

The majority of primary chondrosarcomas are lowrather than high-grade [28] and are of the conventional subtype. Rare subtypes include mesenchymal chondrosarcoma and clear cell chondrosarcoma. In rare circumstances, conventional chondrosarcomas "dedifferentiate" into very high-grade tumours (so-called de-differentiated chondrosarcoma) [29-31] with a poor prognosis.

\section{Undifferentiated pleomorphic sarcoma of bone}

Undifferentiated pleomorphic sarcoma (UPS) of bone is a relatively recent term for sarcomas that do not exhibit a specific line or pattern of differentiation (previously termed malignant fibrous histiocytoma of bone) [32, 33]. UPS of bone is typically high-grade with metastatic rates of at least $50 \%$ [33]. Treatment usually involves neoadjuvant therapy followed by wide excision. Its chemosensitivity and survival rate are similar to osteosarcoma [34]. Occasionally, an undifferentiated pleomorphic sarcoma is found to be a dedifferentiated chondrosarcoma or osteosarcoma after resection.

\section{Chordoma}

Chordomas develop from persistent notochordal elements, and originate from the sacrum (50\%), skull base (30\%), and mobile spine (20\%). Extraskeletal tumours are very rare. Chordoma is a locally invasive, typically low-grade tumour but infrequently (around $5 \%$ ) highly malignant dedifferentiated cases occur [35]. Metastases develop in $30-40 \%$ of patients, typically late in the disease trajectory and usually after local recurrence. Metastases can occur in lung, liver, bone, subcutis, lymph nodes and other sites.

\section{Adamantinoma}

Adamantinoma is a rare, low-grade malignant neoplasm that arises in the tibia, fibula or both bones, although it has rarely been reported in other bones [36]. Adamantinoma accounts for $0.3-1 \%$ of all malignant bone tumours and occurs mostly in young to middle-aged adults (20-40 years of age), with a male-to female ratio of 1.3:1. The tibial shaft (medial or distal) is most commonly affected. The tumour has lytic and sometimes destructive areas which can lead to fracture [37]. Recurrence is late (can be $>20$ years) but frequent (about $30 \%$ ) after incomplete excision. The rate of metastasis is $10 \%$ to $20 \%$, usually to lung [36].

\section{Giant cell tumour of bone}

Giant cell tumours of bone are generally considered benign but locally aggressive tumours; there is a low risk of metastasis, particularly after local recurrence [38]. Giant cell tumours rarely appear before skeletal maturity and most often affect patients between 20 and 30 years of age [39]. Tumours characteristically occur at the end of a long bone in a juxtaarticular location. Histologically tumours contain a proliferation of mononuclear stromal cells amongst which are scattered numerous multinucleated giant cells that have been identified as osteoclasts recruited by the RANK-ligand expressing stromal cells. Tumours cause local destruction of bone and may be associated with a soft tissue mass or pathological fracture [40].

\section{Other malignant mesenchymal tumours}

Very rarely malignant mesenchymal tumours that more commonly arise in soft tissues can present as a primary (often spindle cell) sarcoma of bone. These include spindle cell malignancies such as leiomyosarcoma and fibrosarcoma. In general, spindle cell sarcomas are thought to represent between 2 and $5 \%$ of primary bone 
malignancies. Spindle cell sarcomas arise in a similar age group to chondrosarcoma but the skeletal distribution is similar to osteosarcoma. There is a high incidence of fracture at presentation. Associations with pre-existing conditions (e.g. Paget's disease or bone infarct) or previous irradiation have been reported [41].

\section{Presentation and referral}

The most common symptom of a primary malignant bone tumour is pain, which may gradually increase in intensity [42]. Bone pain at night should always be considered a 'red flag' symptom requiring further investigation. Pain levels may vary and a bone swelling or soft tissue mass may develop later. Even high-grade tumours do not usually cause systemic symptoms; when present these may indicate metastatic disease [42]. The average duration of symptoms is 3 months, although 6 months or longer is not uncommon $[8,43,44]$.

A plain $x$-ray is the first investigation of choice. The presence of any of the following X-ray features is suggestive, but not diagnostic, of a primary bone tumour and should be investigated further, usually following urgent referral to a bone sarcoma MDT:

- Bone destruction

- New bone formation

- Periosteal swelling

- Soft tissue swelling

Additionally, it must be remembered that a 'normal' $\mathrm{x}$-ray does not rule out bone sarcoma; persistent bone pain/night pain should still require urgent MRI scan/ referral to a sarcoma centre. Hip and knee pain in children is often attributed to sporting injury with early 'normal' looking $x$-rays.

In all patients a full clinical history should be taken (including duration, intensity and diurnal variation of pain, prior benign or malignant tumours, family history and previous radiotherapy) and examination performed (with specific attention to the size, consistency, mobility, and location in relation to bone of any mass and palpation of regional and local lymph nodes), considering the most likely diagnosis for a patient of a given age. Recent injury does not rule out a primary bone tumour and should not prevent further examination.

In patients under 40 years of age, investigations prior to referral should include X-ray of the affected bone (in two planes) and simple blood tests [full blood count (FBC), erythrocyte sedimentation rate (ESR), biochemical profile including alkaline phosphatase (ALP)]. Further urgent imaging of the local site with magnetic resonance imaging (MRI) or computed tomography (CT) is usually required, prior to or after referral [8].
In patients over 40 years of age more extensive investigation before referral is appropriate (if it can be done quickly) as the most likely diagnosis is of metastatic carcinoma in bone. Appropriate investigations include CT of chest, abdomen and pelvis, isotope bone scan, and myeloma screen. If the bone lesion is solitary the patient should be referred to a reference centre to exclude a primary malignant bone tumour.

All patients with a possible diagnosis of a primary bone tumour should be referred urgently under the 2 week wait pathway to a fully accredited bone sarcoma MDT $[4,45,46]$. This core principle is embedded in the NICE 'Improving Outcomes for People with Sarcomas' guidance [47], 'Children and Young People with Cancer' guidance [48] and the NICE Quality Standard QS78 Sarcoma [5].

Referral before biopsy is essential to ensure optimal diagnosis and management $[49,50]$ since poorly planned or executed biopsies can compromise future treatment [42].

Networks should ensure GPs are aware of and comply with the urgent referral criteria in the NICE Suspected cancer: recognition and referral guideline NG12 [6] and that GPs and hospital doctors are aware of the local diagnostic pathways for patients with suspected primary bone tumours. There are also referral guidelines specific to Scotland which can be found at healthcare improvements Scotland [51].

\section{UK reference centres}

Royal National Orthopaedic Hospital Stanmore, London Phone 02089095112

Fax 02089095709

www.londonsarcoma.org

www.lsesn.nhs.uk

rno-tr.LondonSarcomaService@nhs.net

Royal Orthopaedic Hospital Northfield, Birmingham

Phone 01216854150

Fax 01216854146

Nuffield Orthopaedic Centre Oxford

Phone 01865738061

Fax 01865738037

North of England Bone and Soft Tissue Tumour Service,

Freeman Hospital

Newcastle upon Tyne

Phone 01912336161 or 01912137708

Fax 01912331328

www.newcastlesarcoma.org.uk

Greater Manchester and Oswestry Sarcoma Service,

Robert Jones and Agnes Hunt Hospital

Oswestry

Phone 08458383429 
Fax 08458383428

Scotland: The Scottish Sarcoma Network, Glasgow Royal Infirmary

Glasgow G4 OSF

Phone 01412321034 or 07951273920

www.ssn.scot.nhs.uk

In Scotland sarcomas are managed under the umbrella of the Scottish Sarcoma Network, which includes centres in Edinburgh, Glasgow and Aberdeen with a shared MDT. Links to the three national networks can be found at the West of Scotland Cancer Network (WoSCAN) [52].

Northern Ireland Sarcoma Network
Musgrave Park Hospital
Stockmans Lane
Belfast
BT9 7JB

BT9 7JB

Tel (028) 95046964

Mob 07885238652

Fax (028) 90637423

\section{Key recommendations}

- The most common symptom of a primary bone tumour is pain which may gradually increase or vary in intensity. Bone pain at night should always be considered a 'red flag' symptom requiring further investigation.

- The presence of pain or a palpable mass arising from any bone requires further investigation. A plain X-ray is the first investigation of choice.

- The presence of radiological features including bone destruction, new bone formation, periosteal swelling and/or soft tissue swelling are suggestive, but not diagnostic, of a bone tumour and require further investigation.

- Networks should ensure that GPs are aware of and comply with the urgent referral criteria in the NICE 'Suspected cancer: recognition and referral guidlines' and 'Cancer referral guidelines for Scotland' and that GPs and hospital doctors are aware of the diagnostic pathways for patients with suspected primary bone tumours.

- All patients with a provisional histological and/or radiological diagnosis of bone sarcoma should have their diagnosis reviewed by a specialist sarcoma pathologist and/or radiologist, both of whom should be part of a bone sarcoma MDT.

\section{Investigation Imaging}

All patients should have X-rays in two planes at presentation.
Further local site imaging should be with MRI [42], including the whole anatomical compartment, the involved bone and adjacent joints [53]. CT is helpful if there is diagnostic uncertainty or MRI is contraindicated, and may better visualise areas of microcalcification, periosteal bone formation and cortical destruction. CT is routinely used in addition to MRI for pelvic tumours. Dynamic contrast enhanced MRI may identify high-grade areas within a chondrosarcoma, and therefore guide biopsy.

Staging investigations for patients with confirmed primary malignant bone tumours should include chest radiography and/or CT. CT is the technique of choice for imaging the chest, pelvis and mandible [53-55]. If indeterminate nodules are detected in the lungs, an interval scan may be indicated. All suspicious chest CTs should be reported by a radiologist experienced in bone sarcoma or sent to an MDT for review.

Whole body bone scintigraphy will detect lesions elsewhere in the skeleton [24]. Whole body MRI and positron emission tomography (PET) may be considered for staging and treatment response evaluation [54, 56-58]. A recent retrospective study of 91 patients with Ewing sarcoma [57], concluded that F-18-deoxy-D-glucose positron emission tomography $\left({ }^{18} \mathrm{FDG}-\mathrm{PET}\right)$ may be sufficient for initial screening of osseous metastases and also identified all patients with bone marrow metastases.

During chemotherapy clinical assessment (pain and clinical measurement) and imaging of the local site and lungs by MRI, chest X-ray and CT may be helpful to evaluate response to chemotherapy $[53,59]$.

\section{Staging systems}

Two staging systems are in widespread use, the Enneking [60] and the TNM system (American Joint Committee on Cancer-AJCC/International Union against cancerUICC) [61].

The Enneking system is based on histological grade ( $\mathrm{I}=$ low and $\mathrm{II}=$ high grade $)$ and extent in relation to the anatomical compartments of the limb $(a=$ intracompartmental, $\mathrm{b}=$ extracompartmental). If the bone cortex is intact and there is no soft tissue mass, the tumour is considered intracompartmental. Stage III tumours have metastases, but can be high or low grade. The TNM (AJCC/UICC) system is based on tumour grade, size and the presence of metastases (Table 2).

\section{Laboratory tests}

There are no specific laboratory tests for the diagnosis of bone sarcoma. However, the following are of prognostic value: erythrocyte sedimentation rate (ESR), alkaline phosphatase (ALP) and lactate dehydrogenase (LDH) [62, 63]. 
Table 2 AJCC/UICC Staging [61]

\begin{tabular}{llll}
\hline Stage & Grade & Size $(\mathbf{c m})$ & Metastases \\
\hline $1^{\circ}$ & Low grade & $\leq 8$ & None \\
$1 \mathrm{~b}$ & Low grade & $>8$ & None \\
$2^{\circ}$ & High grade & $\leq 8$ & None \\
$2 \mathrm{~b}$ & High grade & $>8$ & None \\
3 & Any grade & Any & Skip metastases \\
4 & Any grade & Any & Distant metastases at diagnosis \\
\hline
\end{tabular}

\section{Other baseline assessments}

Around $10 \%$ of Ewing sarcomas metastasise to bone marrow, and therefore bone marrow biopsy should be routinely performed as a staging investigation [42].

Chemotherapy treatment can result in renal, cardiac and auditory dysfunction [64]. Pretreatment evaluation should therefore include baseline renal function testing (e.g. urea, creatinine, glomerular filtration rate) and assessment of cardiac function (e.g. echocardiogram, MUGA [multi-gated acquisition scan]). An audiogram is recommended for patients due to receive cisplatin.

Sperm storage is recommended for male patients of reproductive age. For female patients, a fertility physician may be consulted to discuss options for fertility preservation.

\section{Biopsy}

Biopsy is the definitive diagnostic test. Biopsy of a suspected primary malignant bone tumour should be carried out at a specialist sarcoma reference centre by, or in consultation with, the surgical team who will perform definitive tumour resection [47]. This improves access to modern molecular diagnostic techniques and ensures the biopsy track can be excised at the time of definitive surgery. Inappropriate biopsy can compromise limb salvage or even cure. The principles of biopsy [49] are:

- Biopsy should only be done after local imaging of the affected bone to allow planning of the approach and most representative area to biopsy.

- There should be minimal contamination of normal tissues.

- In many situations, core needle biopsy will be adequate, often guided by ultrasound, X-ray or CT.

- Samples should always be taken for microbiological assessment as well as histology and cytogenetic/ molecular genetic studies.

- Where possible, samples should be snap frozen for storage in a tumour bank for future research studies with patient consent.

- Samples must be interpreted by an experienced bone tumour pathologist.
- The pathology request form should ensure sufficient detail to make a diagnosis, including anatomical site, patient age and the radiological differential diagnosis.

CT-guided biopsies $[65,66]$ are most appropriate for deeper locations (e.g. pelvis) or to target a particular area of concern within the tumour (e.g. a possibly dedifferentiated area in a chondrosarcoma). Frozen sections can help to confirm that lesional tissue has been obtained, but they should not be relied upon for a definitive diagnosis and may use up a significant volume of potentially diagnostic material. Biopsy tracks should be clearly marked with a small incision or tattoo to ensure they are excised at the definitive procedure.

Biopsy of other indeterminate lesions should always be considered if management might change as a result (e.g. entry into a trial or a decision to amputate).

Laminectomy or decompression for spinal tumours should be avoided at diagnosis unless necessary to relieve spinal cord compression, and after consultation with a member of the bone sarcoma MDT.

\section{Pathology}

Pathologists reporting biopsies and/or resections of bone sarcomas should be accredited bone tumour pathologists and members of a bone sarcoma MDT.

Reports should comply with Royal College of Pathologists guidance [67].

The biopsy report should include a description of the specimen, the microscopic findings and the histological diagnosis.

The pathology report relating to the definitive resection specimen should include a gross description recording the location and size (measured in three dimensions in $\mathrm{mm}$ ) of the tumour. It should note the extent of local tumour spread and involvement of specific anatomical compartments. Resection margins should be reported as clear or involved by tumour. The distance (in $\mathrm{mm}$ ) of infiltrating tumour from the nearest resection margin and the nature of tissue at this margin should be specified. The histological features of the tumour and results of relevant further investigations (e.g. immunohistochemistry or molecular genetics) should be recorded. The tumour type (and subtype) should be recorded in keeping with the latest WHO criteria [14]. The tumour type should be coded using the systematized nomenclature of medicine-clinical terms (SNOMED-CT) codes [68].

\section{Molecular genetics and pathology}

Tissue banks are essential for diagnostic and translational research in cancer; therefore, informed consent for tumour banking, analysis and research should be sought according to local practice wherever possible. In 
specialist centres, storage of fresh frozen tissue should be undertaken in every case where consent has been given.

Although most Ewing sarcomas can be recognised morphologically and by immunohistochemical identification of the surface glycoprotein CD99, molecular genetic confirmation of a Ewing sarcoma translocation is recommended, particularly if the clinicopathological presentation is unusual or the histological diagnosis is doubtful. A reference laboratory for Ewing sarcoma diagnosis should have both interphase fluorescence in situ hybridisation (FISH) and reverse transcription-polymerase chain reaction (RT-PCR) technology available [69] and should participate in an external quality assurance programme.

\section{Confirmation of diagnosis}

To confirm the diagnosis and minimise the risk of diagnostic and management errors, all patients with suspected bone tumours should be discussed by a bone sarcoma MDT with a surgeon, radiologist, pathologist and oncologist who have access to the relevant information and biopsy material [47].

\section{Key recommendations}

- Patients with suspected primary bone tumours should have access to timely and appropriate imaging.

- The definitive diagnostic test is a biopsy, which should be carried out at or in consultation with the team in a reference centre.

- All patients should have tissue stored for subsequent investigation with appropriate consent, including frozen tissue, when possible.

- Both the diagnostic and resection specimens should be examined by an accredited bone tumour pathologist who is part of a bone sarcoma MDT. The pathology report should comply with the Royal College of Pathologists guidance.

- In every case the diagnosis must be confirmed by reference to clinical findings, laboratory investigation and radiological imaging at a bone sarcoma MDT.

- Patients with a confirmed diagnosis should be staged according to AJCC criteria.

- Where treatment may have an impact on fertility, patients should be referred to the appropriate reproductive medicine service before commencing treatment.

\section{Overview of management}

As well as having care delivered or supervised by a specialist bone sarcoma MDT, patients should be allocated a key worker. Children, teenagers and young adults should also be discussed at the relevant children's or TYA (young adult) MDT. This requires sufficient specialist staff to ensure age-appropriate care. A bone sarcoma MDT should be properly constituted, adhering to the requirements for core membership of the relevant specialties, and meeting minimum criteria for the number of patients treated each year; they should collect data on patients, tumours, treatment and outcomes as agreed nationally and participate in national audit.

Where possible and where trials are available, patients should be supported to participate in clinical trials. Lists of clinical trials in the National Institute for Health Research portfolio can be found on the UK Clinical Research Network Study Portfolio website [70] and the National Cancer Research Institute Clinical Trials website [71].

\section{Chemotherapy}

Chemotherapy is part of standard treatment for osteosarcoma, Ewing sarcoma, undifferentiated pleomorphic sarcoma and spindle cell sarcoma. Treatment of chondrosarcoma remains predominantly surgical, although chemotherapy may have a role in dedifferentiated and mesenchymal subtypes.

Management usually comprises preoperative neoadjuvant systemic combination chemotherapy, local surgery and post-operative adjuvant chemotherapy [64]. While the main aim of neoadjuvant chemotherapy is to decrease the incidence of a subsequent distant relapse [72, 73], it may also help control the primary tumour.

\section{Surgery}

Decisions about the optimal surgical procedure for the primary tumour (i.e. limb salvage or amputation) require MDT discussion, considering tumour size and involvement of anatomical structures, response to neoadjuvant therapies and patient preference. Surgical reconstruction may be influenced by patient and surgeon choice and should follow open discussion of the risks and benefits of available options and expected functional outcomes.

The aim of curative surgery is to resect the whole tumour with adequate margins. Where possible, wide en-bloc resection of the affected part of the bone and involved soft tissue should be performed. Close surgical margins may be marked with (MRI-inert) haemo-clips placed in the surgical field. In Ewing sarcoma, surgery should involve removal of all anatomical structures involved in the original prechemotherapy tumour volume where feasible. The specimen should be orientated to allow the pathologist to describe the anatomical location and thickness of surgical margins.

Surgical excision of local recurrence or metastatic disease requires discussion in a bone sarcoma MDT. 


\section{Requirements for the surgical report}

The surgeon should describe the procedure performed and the tissues resected. The planned surgical margin should be identified, along with areas of concern where the resection was close to tumour or gross tumour was encountered. The type of reconstruction should be described as well as postoperative care, including expected rehabilitation. The use of prophylactic antibiotics and thromboprophylaxis (e.g. mechanical and/or chemical agents) should be clearly stated.

\section{Radiotherapy}

Radiotherapy is frequently used in the definitive management of the primary tumour for Ewing sarcoma, but the relative radio-resistance of osteosarcoma and chondrosarcoma means it is only used as definitive treatment if there is no surgical option. Radiotherapy is not given routinely post-operatively, although it may be used in selected high-risk cases. However, radiotherapy has a palliative role in all tumour types.

Although considered exploratory, heavy particle therapy with protons or carbon ions, often in combination with photons, is increasingly used to treat unresectable primary bone sarcomas [74-76]. Excellent outcomes are reported for skull base chondrosarcomas or chordomas in which proton beam radiotherapy combined with surgery can achieve local control rates of approximately $70-90 \%$ [77-79]. In unresectable or incompletely resectable osteosarcoma the five-year disease free survival (DFS) was $65 \%$, and the 5-year overall survival (OS) was $67 \%$ [80]. High local control rates have also been achieved in sacral chordomas $[81,82]$.

At present there is no proton facility in the United Kingdom, but cases can be submitted to the UK Proton Panel to consider funding for treatment overseas. Referral guidelines can be found at the UK NHS England Commissioning website [83].

\section{Prevention and management of pathological fracture}

Patients with an existing or impending pathological fracture associated with a suspected primary bone tumour should be managed with external splintage or immobilisation and appropriate pain control until a diagnosis is established by local imaging (MRI and/or CT) and biopsy. Internal fixation is contraindicated.

Although pathological fracture is an adverse prognostic factor for survival in osteosarcoma, and is likely to be associated with an increased risk of local recurrence [84], it does not preclude limb sparing surgery [85].

Fractures often heal during neoadjuvant chemotherapy and allow subsequent resection of the tumour and involved soft tissues. Amputation may still be indicated if tumours fail to show a radiological response and/or resection of the tumour and the contaminated area cannot safely leave a useful limb [86]. Adjuvant radiotherapy may decrease the risk of local recurrence in osteosarcoma and may have a role in other tumour types after pathological fracture [87].

\section{Thoracotomy}

Pulmonary metastatectomy may be indicated in the presence of oligometastatic disease where the patient can be rendered disease free. Thoracotomy with manual exploration of both lungs is strongly recommended, even when imaging studies suggest unilateral disease. Thoracoscopic techniques are strongly discouraged, as they lack sensitivity and may be associated with an increased risk of intraoperative tumour dissemination [88].

\section{Key recommendations}

- All patients with a confirmed diagnosis of bone sarcoma should have their care supervised by a bone sarcoma MDT and be allocated a key worker. Children, teenagers and young adults should also be discussed at the relevant children's or TYA (young adult) MDT.

- Networks should ensure that they meet the needs of children and young people with cancer with sufficient specialist staff and care and facilities appropriate to the child or young person's age.

- A bone sarcoma MDT should meet minimum criteria for the number of patients treated in each year and adhere to the requirements for core membership of the relevant specialties.

- All bone sarcoma MDTs should collect data on patients, tumours, treatment and outcomes as agreed nationally.

- Patients should undergo definitive resection of their sarcoma by a surgeon who is a core or extended member of a bone sarcoma MDT or by a surgeon with tumour site specific or age appropriate skills in consultation with the bone sarcoma MDT.

- When considering the local treatment of bone tumours, options for amputation or limb sparing surgery should be tailored to the needs of the patient.

- Chemotherapy and radiotherapy are important components of the treatment of some patients and should be carried out at designated centres by appropriate specialists as recommended by a bone sarcoma MDT.

- For pulmonary metastatectomy, open thoracotomy is recommended over endoscopic techniques.

\section{Specific treatment}

\section{Osteosarcoma}

Adverse prognostic factors for osteosarcoma include detectable metastases at presentation, axial or proximal 
extremity tumour site, large tumour volume, elevated ALP or LDH, older age, high body mass index (BMI) at diagnosis, poor histological response to preoperative chemotherapy or pathological fracture [62, 89-91]. There is some evidence that females may have better outcomes than males [91] and patients $>18$ years may have poorer outcomes than younger patients [92].

\section{Localised disease}

Curative treatment for high-grade osteosarcoma consists of surgery and chemotherapy [88, 93]. Compared with surgery alone, multimodal treatment of high-grade osteosarcoma increases survival from only $10-20 \%$ to around $60 \%[94,95]$. Whenever possible, patients with osteosarcoma should receive chemotherapy within a prospective trial. Chemotherapy is also recommended for older patients with osteosarcoma using adapted protocols [96].

Treatment commonly takes 6-9 months, comprising 10 weeks of neoadjuvant therapy, surgical resection and adjuvant chemotherapy.

Although neoadjuvant treatment is not proven to add survival benefit over postoperative chemotherapy alone, advantages include: rapid improvement in symptoms; early treatment of micrometastatic disease; facilitation of resection in responsive tumours; it allows time to manufacture customised endoprosthesis and provides prognostic information about histological response [42, $45,97]$.

The most accepted regimen is induction therapy with MAP (high-dose methotrexate (HDMTX), doxorubicin and cisplatin). This is recommended in the UK for patients with potentially resectable tumours [98] and was chosen for the EURAMOS study ${ }^{1}$ (Table 3).

If not tolerated, the regimen may be modified to AP alone for patients $>40$ years old. Impaired renal function can cause delayed clearance of methotrexate resulting in mucositis and nephrotoxicity and therefore close monitoring is required. Combination regimens without methotrexate can be effective in patients intolerant of HDMTX or where pharmacokinetic monitoring is not available [99].

The goal of surgery is to safely remove the whole tumour whilst preserving as much function as possible. Most patients with extremity tumours are candidates for limb salvage if adequate surgical margins can be achieved. Where possible, wide surgical margins should be achieved to reduce the risk of recurrence [100]. It is accepted that a good (>90\%) histological necrosis rate

\footnotetext{
${ }^{1}$ EURAMOS is a collaboration of the Children's Oncology Group (US) the Co-operative Osteosarcoma Study Group (European) the European Osteosarcoma Intergroup and the Scandinavian Sarcoma Group. Collectively these groups represent the largest ever clinical experience in osteosarcoma.
}

after chemotherapy may allow a closer margin of excision to be considered safe. In patients with a poor response to chemotherapy and 'close' margins there is insufficient evidence to advise as to whether amputation offers a better outcome even accepting the increased rate of local recurrence with limb salvage [86].

The benefit of adjuvant therapy compared with surgery alone was demonstrated many years ago [104] and long-term ( $>25$ years) follow-up has shown that a statistically significant survival benefit is maintained [105]. Adjuvant therapy may involve the same regimen as the induction phase or may be modified, but the ideal combination regimen and the optimal treatment duration for certain clinical situations are yet to be defined [93, 106].

Immune modulation has been proposed as a possible treatment in bone sarcomas. The immune modulator liposomal muramyl tripeptide (mifamurtide) added to postoperative chemotherapy demonstrated a statistically significant advantage in overall survival and a trend in event-free survival in a large randomised trial [101] and has been approved in Europe for patients under 30 with completely resected localised osteosarcoma.

Interferon has also been investigated in in vitro and xenograft models [107] but its evaluation in the EURAMOS-1 trial showed no apparent advantage [108, 109].

Histological response to induction therapy has been accepted as a robust prognostic indicator [62, 91, 100, $110]$. Imaging techniques to identify response preoperatively, such as FDG-PET [111] and dynamic (diffusion weighted) MRI [112] are under investigation.

Changing postoperative chemotherapy on the basis of response has not been shown to improve outcome, and is not recommended at present [42].

The use of haematopoietic growth factors to increase dose intensity has not consistently resulted in improved survival of osteosarcoma patients [95] but may limit morbidity associated with myelosuppression. Prophylactic antibiotics are now recommended for cancer patients at risk of neutropenic sepsis [113].

\section{Central, parosteal and craniofacial osteosarcomas}

Low-grade central and parosteal osteosarcoma are variants with lower malignant potential, for which treatment is surgical. Histological examination of the resected tumour may show high grade areas in which case treatment should be with chemotherapy as for conventional osteosarcoma.

The exact role of chemotherapy has not been defined for periosteal and jaw osteosarcoma but experience shows that standard chemotherapy can be given and should be considered for all patients at presentation as part of evaluation by an experienced MDT. Jaw and other 
Table 3 Sarcoma advisory group guidelines for osteosarcoma

\begin{tabular}{|c|c|c|c|}
\hline Category & 1st line & 2nd line & 3rd line and other \\
\hline Resectable $<30$ years & $\begin{array}{l}\text { Doxorubicin, cisplatin } \\
\quad \text { methotrexate } \pm \text { mifamurtide [101] }\end{array}$ & Ifosfamide and etoposide [102] & $\begin{array}{l}\text { Gemcitabine and docetaxe } \\
\text { [103] or oral etoposide }\end{array}$ \\
\hline Other & Doxorubicin, cisplatin \pm methotrexate $[101]$ & Ifosfamide, etoposide \pm methotrexate & $\begin{array}{l}\text { Gemcitabine and docetaxe } \\
\text { [103] or oral etoposide }\end{array}$ \\
\hline
\end{tabular}

Taken from: London and South East Sarcoma Network (LSESN) Guidelines [98]

craniofacial osteosarcomas present specific problems for management, especially to achieve local control, and must always be referred to a bone sarcoma MDT before surgery. ${ }^{18} \mathrm{FDG}$ PET is more reliable than standard imaging in evaluating response to neoadjuvant chemotherapy in craniofacial bone sarcomas and may correlate better with outcome than histological response [114].

\section{Metastatic disease}

Patients presenting with metastatic osteosarcoma are a heterogeneous group and may be treated using the same regimens as for non-metastatic osteosarcomas, provided that surgical resection of all disease sites is deemed feasible [115]. Approximately $30 \%$ of patients with primary metastatic osteosarcoma and over $40 \%$ of those who achieve complete surgical remission become long-term survivors [93].

\section{Recurrent disease}

The prognosis for recurrent disease is poor, with longterm post-relapse survival of less than a third [93]. Early relapse and distant non-lung metastases are associated with a poorer prognosis [116].

Treatment for locally recurrent or metastatic osteosarcoma is primarily surgical, if possible. Pulmonary metastatectomy can lead to long term survival if all metastases can be completely removed [117]. More than a third of patients with a second surgical remission survive for over 5 years, and patients with multiple recurrences may be cured as long as recurrences are resectable: repeated thoracotomies are often warranted [118]. However, if pulmonary metastases are inoperable the disease is almost universally fatal.

The role of second-line chemotherapy for recurrent osteosarcoma is less well defined than that of surgery and there is no accepted standard regimen $[93,115]$. The choice of agents may take into account the prior diseasefree interval; suggested regimens are shown in Table 3 [98].

Second-line chemotherapy is associated with limited prolongation of survival in patients with inoperable metastases, but a positive benefit in operable disease was observed in one series [119-121]. Radiotherapy, including samarium, may palliate inoperable sites $[4,122]$.
Agents targeting the epidermal growth factor receptor are investigational in patients with unresectable disease failing first-line therapy [123].

\section{Treatment evaluation}

Assessment of response is usually only possible after several cycles of chemotherapy. Changes in the size and ossification of the tumour do not reliably reflect response to neoadjuvant chemotherapy. However, reduction in peritumoural oedema seen on MRI indicates a good treatment response [124]. A small study showed PET/CT is more accurate than MRI for following bone lesions $[58,125]$ but confirmation in larger prospective studies is needed.

\section{Key recommendations}

- Treatment for osteosarcoma involves chemotherapy and surgery under the care of a specialist bone sarcoma MDT.

- Patients should be informed about relevant clinical trials and supported to enter them.

- First line standard treatment is MAP chemotherapy for patients under 40 years.

- Mifamurtide may be offered to patients without metastases after surgery.

- Treatment of the primary tumour should be surgical removal of the tumour with negative surgical margins where feasible.

- The adequacy of local clearance should be assessed by considering the response to chemotherapy and the surgical margin.

- Radiotherapy can be offered for local control where surgical removal is not possible.

- Where pulmonary metastases are present successful excision may prolong survival.

- The primary treatment of recurrent disease is surgical although there is a role for chemotherapy.

\section{Ewing sarcoma}

Prognostic factors for Ewing sarcoma include axial location, tumour volume, raised serum LDH, and older age ( $>15$ years). A poor histological response to preoperative chemotherapy and incomplete or no surgery for local therapy are further adverse prognostic factors [89, 126-128]. 
Ewing Sarcoma is a radiosensitive tumour. Radiotherapy may be used in combination with surgery, where there is a poor response to chemotherapy (radiological or histological), if there are concerns about surgical resection margins $[129,130]$ or if the anatomical site makes complete resection impossible. Radiotherapy may be given to the primary tumour site preoperatively, postoperatively or as definitive local therapy where surgery is not possible.

With surgery or radiotherapy alone, 5-year survival for Ewing sarcoma is $<10 \%$. With treatment in current multimodality trials including chemotherapy, 5-year survival is between 60 and $70 \%$ in localized and 20 to $40 \%$ in metastatic disease [4].

\section{Localised disease}

All current trials employ 10 to 12 months of treatment comprising three to six cycles of neoadjuvant chemotherapy, followed by local therapy and a further six to ten cycles of chemotherapy usually given at 2 or 3 week intervals and based on current agreed national or international protocols. Agents considered most active include doxorubicin, cyclophosphamide, ifosfamide, vincristine, dactinomycin and etoposide [23, 89, 127, 130-139]. The LSEN guidelines [98] are summarized in Table 4. Virtually all active protocols are based on four to six drug combinations of these agents. Chemotherapy intensity is positively associated with outcome: superior outcome has been demonstrated with compressed 2 weekly chemotherapy [140]. High dose chemotherapy with blood stem cell transplantation is still investigational [141].

Local treatment may comprise surgery or radiotherapy or both. Individual decisions about local therapy are frequently complex and should only be made by a bone sarcoma MDT in conjunction with the patient and their family if appropriate. It is also recommended that the MDT's treatment plan is then discussed at the UK National Ewings MDT (ROH-tr.ewingsMDT@nhs.net) and entry into a clinical trial considered. At the time of writing (2015), the EE2012 trial is still open [151].

Complete surgery is regarded as the best treatment for local control but may not always be feasible. There is increasing recognition of the importance of treating all tissue initially involved by tumour, even if there has been a good response to chemotherapy. If this volume cannot confidently be removed surgically then radiotherapy should be used.

Indications for planned preoperative radiotherapy include poor response to induction chemotherapy, expected marginal resection, or if radiotherapy is anticipated to be required and the bone sarcoma MDT judges there is a technical advantage to preoperative radiotherapy.
Preoperative radiotherapy may also be useful in particular anatomical locations (e.g. pelvis, rib) when preoperative treatment allows the tumour volume to be defined more easily, or when treatment volumes will be smaller than in the post-operative setting. Radiotherapy alone should be considered if complete surgery is impossible or would be very disabling, (e.g. for sacral tumours crossing the midline) [152, 153]. If standard conformal radiotherapy will not achieve an adequate dose to the tumour, techniques such as IMRT (intensity modulated radiotherapy) may deliver a higher dose [154-156]. Insertion of pelvic spacers can displace bowel away from pelvic tumours, facilitating delivery of a higher dose and preventing long term bowel toxicity [157]. Proton beam radiotherapy may be considered when there is a dosimetric advantage over photon radiotherapy in achieving the optimal radiotherapy dose due to proximity to critical structures such as spinal cord, and for younger patients having curative treatment in order to reduce the risk of radiation-induced second malignancy. Applications for treatment are made via the UK Proton Panel [83]).

Toxicities leading to death have been observed in some patients who received high dose large volume radiotherapy following busulpan-melphalan high dose chemotherapy (BuMel HDT). BuMel HDT may therefore compromise the delivery of effective radiation doses to central axial sites. In patients with an indication for radiotherapy, the patient should not be offered BuMel HDT if there are critical organs such as gut, spinal cord, brain or significant volumes of lung in the fields, unless the technique used can limit the dose to critical organs.

Specific indications for post-operative radiotherapy include (Taken from: Euro-Ewing-2012 radiotherapy guidelines [158]):

- positive surgical margins with microscopic residual disease (R1 excision; $<1 \mathrm{~mm}$ or tumour up to edge of resection specimen) if further surgery to achieve negative margins is not possible.

- positive surgical margins with macroscopic residual disease (R2 excision), if further surgery to achieve negative margins is not possible (this should be an unusual situation).

- if all tissues involved by the original pre-chemotherapy tumour volume have not been excised, even if the surgical margins are negative.

- if there is a poor histological response ( $\leq 90 \%$ necrosis) to pre-operative chemotherapy, even if the surgical margins are negative.

- a displaced pathological fracture of bone at primary site (unless it is possible to excise all contaminated tissue). 


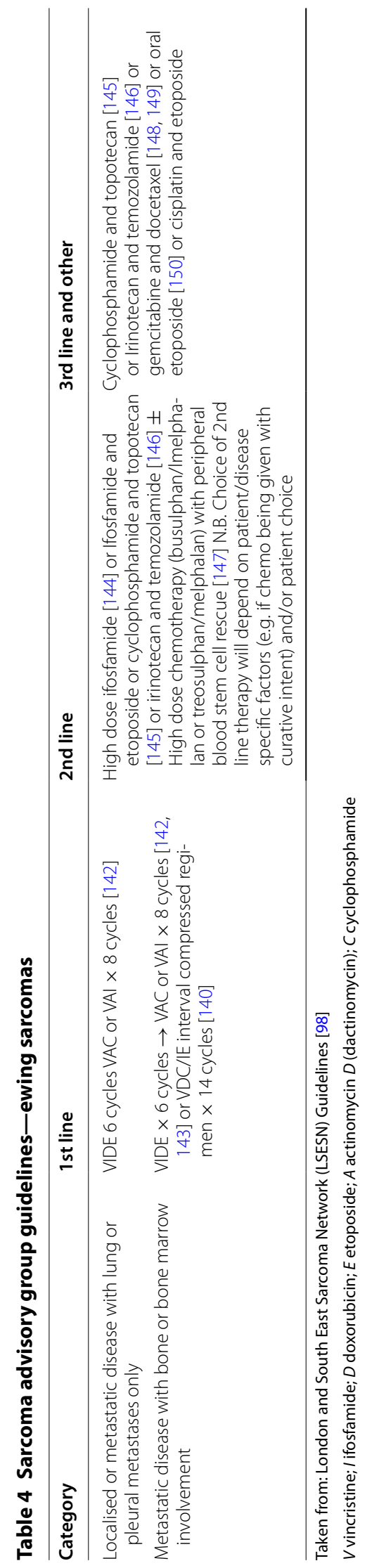


- certain tumour sites where local control is judged to be more difficult to achieve e.g.:

- Spine and paraspinal sites-in these sites excision is rarely complete, and is often intra-lesional.

- Pelvis and sacrum-in these sites it is frequently difficult or impossible to be sure that the entire prechemotherapy tumour volume has been excised.

- Rib tumours when presenting with a pleural effusion.

Reasons for deciding against radiotherapy may include:

- Concerns about impaired healing of the wound or biological reconstruction following surgery and radiotherapy.

- Concerns about morbidity of radiotherapy in young patients.

- Concerns about the increased risk of infection of a metallic prosthesis following radiotherapy.

- Concerns about the risk of a radiation-induced malignancy.

Definitive radiotherapy is advised only for inoperable lesions. Inoperability is determined during bone sarcoma MDT discussion. Inoperable tumours are those which cannot be resected completely, or are in anatomical sites where complete surgery would result in unacceptable morbidity or have a high risk of significant complications. Suggested radiotherapy doses are given in Table 5.

\section{Metastatic and recurrent disease}

Around $26 \%$ of patients with Ewing sarcoma have metastatic disease at presentation (10\% lung, $10 \%$ bones/ bone marrow, $6 \%$ combinations or others) [159]. Bone metastases confer a poorer outcome than lung/pleural metastases $(<21 \%$ compared with $55 \%$ 5-year relapse free survival) [143].

Patients with metastases at diagnosis are treated similarly to those with localised disease but have a poorer prognosis. Several non-randomised trials have evaluated more intensive, time compressed or high-dose chemotherapy approaches, followed by autologous stem cell rescue, demonstrating a possible advantage for patients under 14 years of age $[143,147]$. Whole lung radiotherapy is indicated in patients with pulmonary disease, and may prolong survival. However, firm data are lacking and a systematic review failed to confirm a survival advantage [160]. Radiation doses are given in Table 6.

A recent review of stereotactic body radiotherapy (SBRT) for metastatic and recurrent Ewing sarcoma and osteosarcoma reported on 14 patients with 27 osseous or pulmonary lesions. Estimated local control at 2 years in the lesions treated with curative intent was $85 \%$. However, there was significant toxicity especially if concurrent chemotherapy and re-irradiation were given [161].

The role of surgical resection of residual metastases is less well defined. Patients with bone or bone marrow metastases and patients with recurrent disease still fare poorly, with 5-year survival rates of between 10 and $45 \%$ $[24,162,163]$.

Guidance on the management of small suspicious lung nodules is available in trial protocols $[108,131]$.

Patients relapsing more than 2 years after diagnosis and without bone marrow or multiple bone involvement have a better outcome than others $[126,162,164,165]$.

Table 5 Radiotherapy dose and fractionation for ewing sarcoma

\begin{tabular}{ll}
\hline Setting & Dosage \\
\hline Pre-operative radiotherapy & $\begin{array}{r}\text { The total dose for preoperative irradiation is } 50.4 \text { Gy in } 28 \text { fractions in a single phase to the PTV. If there are concerns } \\
\text { about organ tolerance or wound healing, then this dose can be reduced to } 45 \text { Gy in } 25 \text { Gy fractions }\end{array}$ \\
$\begin{aligned} \text { Post-operative radiotherapy } \\
\text { The total dose for postoperative radiotherapy is } 54 \text { Gy in } 30 \text { fractions, delivered as } 45 \text { Gy in } 25 \text { fractions to PTV1, and } 9 \text { Gy } \\
\text { in } 5 \text { fractions to PTV2 }\end{aligned}$ \\
$\begin{aligned} \text { The total dose for definitive radiotherapy is } 54 \text { Gy in } 1.8 \text { Gy fractions, delivered as a single phase. A boost of } 5.4 \text { Gy in } 3 \\
\text { fractions may be considered if desired, keeping within standard normal tissue dose constraints }\end{aligned}$ \\
\hline
\end{tabular}

Fractionation: conventionally fractionated radiotherapy (once daily fractions, five 1.8 Gy fractions per week) is the preferred fractionation schedule. In very young children, fractionation using $1.6 \mathrm{~Gy}$ fractions may be considered

Taken from: Euro-Ewing-2012 radiotherapy guidelines [158]

\section{Table 6 Radiotherapy doses for whole lung radiotherapy}

Whole lung radiotherapy The dose for whole lung radiotherapy is 15 Gy in 10 fractions for patients $<14$ years, or 18 Gy in 12 fractions for patients $\geq 14$ years. Dose may be specified to $100 \%$ for an optimised plan, or to the mid plane dose (MPD) for simulated opposed fields. However, it should be noted that this will result in a dose of approximately $10 \%$ higher in the lungs than that prescribed, and so optimisation of dosimetry is recommended if fields are simulated 
Doxorubicin therapy is usually not feasible after relapse because of previously administered cumulative doses. Chemotherapy regimens are not standardised and currently often comprise alkylating agents (cyclophosphamide, high-dose ifosfamide) in combination with topoisomerase inhibitors (etoposide, topotecan) or irinotecan with temozolomide [23, 133, 137, 138]. Given the poor outcomes after relapse, patients should be recruited to prospective clinical trials to investigate the role of second-line/experimental therapies wherever possible. At time of writing, an international trial, rEECur, is open to recruitment [151]. Radiotherapy may be helpful to palliate local symptoms.

\section{Treatment evaluation}

Change in the size of the soft tissue mass is easily evaluated on MRI, and is a reliable indicator of tumour response [166]. Dynamic MRI is not as reliable as in osteosarcoma, as remaining small tumour foci may not be detected. Sequential FDG PET evaluation and whole body MRI scanning is under evaluation [53, 112].

Disease progression during chemotherapy may mandate changes in treatment or earlier primary local control measures. A radiological increase in tumour size may be due to necrosis rather than tumour progression.

\section{Key recommendations}

- For Ewing sarcoma, systemic treatment with chemotherapy is standard. All new cases of Ewing's sarcoma of bone should be discussed at the National Ewing Multidisciplinary Team meeting.

- When treating the primary tumour with curative intent, all of the pre-chemotherapy volume should be treated with surgery, radiotherapy or both.

- If radiotherapy is indicated (e.g. the anatomical location of the tumour makes complete resection impossible or there has been an incomplete response to chemotherapy as identified radiologically), then preoperative radiotherapy may be advantageous.

- Patients with relapsed/progressive disease should be considered for clinical trials.

\section{Chondrosarcoma}

Assessing the grade of chondrosarcomas is difficult and variation in opinion is common, even between experts [28]. The diagnosis of chondrosarcoma requires discussion in a bone sarcoma MDT. Surgery is the treatment of choice.

Low grade cartilage tumours may recur locally but are unlikely to metastasise. Biopsy-confirmed low grade central chondrosarcomas in extremity long bones can be managed by complete curettage with or without adjuvant measures (e.g. phenol, cement, cryotherapy) with a high chance of success. Low grade peripheral chondrosarcomas (arising from osteochondromas) should be completely surgically removed, aiming to excise the tumour with a covering of normal tissue.

Higher grade chondrosarcomas (including clear cell chondrosarcoma) and all chondrosarcomas of the pelvis or axial skeleton should be surgically excised with wide margins $[29,30]$.

Mesenchymal chondrosarcoma may be responsive to chemotherapy and some patients may be considered for adjuvant or neoadjuvant therapy [114]. There is uncertainty about the chemotherapy sensitivity of dedifferentiated chondrosarcoma but it can be treated like osteosarcoma, although survival is poorer [31]. Survival after a diagnosis of dedifferentiated chondrosarcoma remains dismal. Complete excision is recommended if feasible, but there is a very high risk of local recurrence following pathological fracture. If wide margins cannot be reliably achieved with limb salvage, then amputation may maximize the chances of local control but there remains a high risk that metastases will develop.

\section{Key recommendations}

- Diagnosis of a chondrosarcoma requires discussion in a bone sarcoma MDT.

- Management of chondrosarcoma is surgical excision with wide margins for all but low grade central limb chondrosarcoma where curettage may be adequate.

- There are no data to support the routine use of chemotherapy.

\section{Undifferentiated pleomorphic sarcomas.}

Treatment strategies mimic those of osteosarcoma, with age-adjusted chemotherapy and complete en-bloc resection including any soft tissue component if possible.

\section{Chordoma}

Assessment in a specialist centre with expertise in managing chordomas is essential. To date, conventional therapy for chordoma has been complete surgical resection [167]. High dose radiotherapy using proton beams or carbon ions may be used post-operatively, and are promising alternatives to surgery for some patients, particularly those with high sacral tumours $[74,81,82]$.

Surgical excision of tumours of the skull base or cervical spine should aim to remove as much tumour as possible, whilst preserving neurological function and therefore quality of life. R0 resection is rarely possible. Eight studies (summarized by Stacchiotti et al. [35]) have shown that surgery ( $\mathrm{R} 1$ and $\mathrm{R} 2$ resections) followed by radiotherapy in selected patients produced 5-year estimated 
overall survival of $55-86 \%$ in patients with chordoma of the skull base and/or cervical spine.

Metastases are rare but local recurrence is common and difficult to cure [168]. Treatment for local recurrence may include surgery and/or radiation therapy and/or systemic treatment (Table 7) [4, 35]. Molecular targeted agents may be effective $[169,170]$.

\section{Other bone sarcomas}

Prognosis and prognostic factors after a diagnosis of spindle cell sarcoma are similar to those of patients with osteosarcoma [41, 171, 172]. Treatment should be similar.

Adamantinoma is a malignant tumour occurring in the tibia. Most are low grade but higher grade areas in the primary tumour may require systemic therapy. Complete excision is the treatment of choice.

\section{Giant cell tumours of bone}

Giant cell tumours of bone require highly specialised treatment and all patients should be referred to a specialist bone sarcoma MDT for diagnosis and to coordinate treatment. Curettage alone is associated with a high risk of local recurrence (up to $50 \%$ ). Although there is no randomized controlled trial evidence, numerous case series suggest improved local control if adjuvants such as high speed burring and cement are used.

Denosumab is a novel RankL inhibitor which has been shown in clinical trials to suppress the formation and activity of osteoclasts. It is licensed for use by the European medicines agency from 2014. Denosumab is indicated in inoperable cases or those where the morbidity of surgery would be excessive. Denosumab is given as a monthly subcutaneous injection after three loading doses at weekly intervals. All patients require daily calcium and vitamin D supplements and females must avoid pregnancy. Significant side effects include hypocalcaemia, osteonecrosis of the jaw and atypical fractures [173, 174].

Emerging evidence suggests that whilst initial control is excellent (96\%), later recurrences can arise and most tumours recur if the drug is stopped (after around 9 months). Hence in inoperable cases life-long treatment may be required. The consequences of this, particularly in younger patients, are not known.

Using denosumab to reduce the size of a giant cell tumour prior to surgery may be advantageous but surgery should incorporate the extent of the original tumour to avoid recurrence. While clear guidance on the optimal duration of pre-operative treatment has yet to emerge, prolonged exposure to denosumab may make subsequent curettage more difficult. Treatment for up to 6 months before surgery is a reasonable pragmatic approach.

\section{Follow-up}

Follow-up after treatment aims to detect local recurrence, to detect metastatic disease for which treatment might be beneficial, to manage the long term toxicity of chemotherapy and radiotherapy and to look for long term complications of surgical treatment [4]. Local recurrences are often first detected by patients and therefore they should be given information about what to do if local recurrence is suspected.

The clinical follow-up of patients treated for high-grade tumours should include physical examination of the primary tumour site, and assessment of the functional outcome and possible complications of any reconstruction. Local and chest imaging should be included. Evidence for the optimum frequency of follow-up and the best imaging investigations is lacking although a recently reported randomised controlled trial showed no benefit of greater frequency of follow-up with regular cross sectional imaging over standard follow-up [178]. However, current protocols recommend follow-up at intervals of 2-4 months for the first 3 years after completion of therapy, every 6 months for year 4 and 5 and annually thereafter [24, 93].

For low grade bone sarcomas, the frequency of follow-up visits can be reduced to 4-6 monthly for 2 years and then annually. Late metastases as well as local

Table 7 Sarcoma advisory group guidelines-bone sarcomas

\begin{tabular}{|c|c|c|c|c|}
\hline Sarcoma type & Category & 1 st line & 2nd line & 3rd line and other \\
\hline $\begin{array}{l}\text { Other high grade bone sar- } \\
\text { comas including malignant } \\
\text { fibrous histiocytoma, leio- } \\
\text { myosarcoma, angiosarcoma, } \\
\text { spindle cell sarcoma, dedif- } \\
\text { ferentiated chondrosarcoma }\end{array}$ & & $\begin{array}{l}\text { Doxorubicin, } \\
\text { cisplatin } \pm \text { methotrexate } \\
{[101]}\end{array}$ & $\begin{array}{l}\text { Ifosfamide, } \\
\text { etoposide } \pm \text { methotrexate } \\
{[102]}\end{array}$ & $\begin{array}{r}\text { Gemcitabine and } \\
\text { docetaxel [103] }\end{array}$ \\
\hline Giant cell tumour & $\begin{array}{l}\text { Locally advanced } \\
\text { unresectable/metastatic }\end{array}$ & Denosumab [175] & & \\
\hline Chordoma & $\begin{array}{l}\text { Locally advanced, unresectable or } \\
\text { metastatic: non-dedifferentiated } \\
\text { dedifferentiated }\end{array}$ & $\begin{array}{l}\text { Imatinib [171] doxorubicin } \\
\text { or doxorubicin and } \\
\text { cisplatin [176] }\end{array}$ & $\begin{array}{l}\text { Addition of sirolimus [170] } \\
\text { or Sunitinib [177] }\end{array}$ & \\
\hline
\end{tabular}

Taken from London and South East Sarcoma Network (LSESN) guidelines [98] 
recurrences and failure of reconstructions may occur more than 10 years after diagnosis in all tumours and there is no universally accepted stopping point for follow-up [4].

It is important to evaluate the long-term toxicity effect of chemotherapy and radiotherapy as well as immediate chemotherapy-related complications [64]. Monitoring for late effects should be undertaken, depending on the treatment given and in conjunction with late effect services when available $[127,179,180]$.

Secondary cancers may arise in survivors of bone sarcomas, either related to or independent of irradiation. Secondary leukaemia, particularly acute myeloid leukaemia may rarely be observed following chemotherapy as early as $2-5$ years after treatment $[181,182]$.

\section{Key recommendations}

- Standard follow-up for all sarcoma cases is currently chest X-ray and clinical review. The role of regular cross sectional imaging remains uncertain.

- At the end of treatment patients should receive information about the risk of local and systemic recurrence.

- Patients should have access to services for the late effects of treatment including chemotherapy, radiotherapy, surgery and psychsocial support.

\section{Authors' contributions}

All authors contributed to the content of the manuscript. All authors read and approved the final manuscript.

\footnotetext{
Author details

${ }_{1}^{1}$ Newcastle upon Tyne Hospitals NHS Foundation Trust, Freeman Hospital, Newcastle upon Tyne NE7 7DN, UK. ${ }^{2}$ Nuffield Orthopaedic Centre, Oxford OX3 7LD, UK. ${ }^{3}$ Royal Manchester Children's Hospital, Manchester M13 9WL, UK. ${ }^{4}$ Royal Orthopaedic Hospital, Birmingham B31 2AP, UK. ${ }^{5}$ The Royal Marsden, Sutton SM2 5PT, UK. ${ }^{6}$ Birmingham Children's Hospital, Birmingham B4 6NH, UK. ${ }^{7}$ Queen Elizabeth Hospital, Birmingham B15 2TH, UK. ${ }^{8}$ University College Hospital, London NW1 2PG, UK.
}

\section{Acknowledgements}

We would like to thank the following people for reading and commenting on the final manuscript: Lindsay Campbell, Glasgow, Scotland; Rod Duncan, Glasgow, Scotland; John Barr, Belfast, Northern Ireland; CR Chandraseka, Liverpool, England; Dermot Murphy, Glasgow, Scotland; Angela Edgar, Edinburgh, Scotland; Lin Russell, Birmingham, England; Ivon Van Heugten, Changing Faces, London, England.

\section{Competing interests}

The authors declare that they have no competing interests.

Received: 3 February 2016 Accepted: 9 March 2016 Published online: 04 May 2016

\footnotetext{
References

1. National Health Service (NHS) Highly Specialised Commissioning Group. http://www.england.nhs.uk/commissioning/spec-services/npccrg/group-b/b12/. Accessed 30 Jan 2014.

2. Grimer R, Athanasou N, Gerrand C, Judson I, Lewis I, Morland B, Peake $D$, Seddon B, Whelan J. UK guidelines for the management of bone sarcomas. Sarcoma. 2010;317462:14. doi:10.1155/2010/317462.
}

3. National Comprehensive Cancer Network. NCCN Clinical Practice Guidelines in Oncology. Bone Cancer, Version 1.2015. http://www.ncen. org/professionals/physician_gls/pdf/bone.pdf. Accessed 02 Sep 2015.

4. The ESMO/European Sarcoma Network Working Group. Bone sarcomas: ESMO clinical practice guidelines for diagnosis, treatment and followup. Ann Oncol. 2014;25(Suppl 3):113-23.

5. National Institute for Health and Care Excellence (NICE) Quality Standard QS78 Sarcoma; 2015. http://www.nice.org.uk/guidance/qs78. Accessed 02 Feb 2015.

6. National Institute for Health and Care Excellence (NICE) Suspected cancer: recognition and referral NICE guideline [NG12]; 2015. http:// www.nice.org.uk/guidance/ng12. Accessed 21 Sep 2015.

7. National Cancer Intelligence Network (NCIN). Bone sarcoma incidence and survival. Tumours diagnosed between 1985 and 2009. Report R12/05 October 2012 www.ncin.org.uk/. Accessed 02 Feb 2015.

8. Grimer RJ, Briggs TR. Earlier diagnosis of bone and soft tissue tumours. J Bone Joint Surg Br. 2010;92(11):1489-92. doi:10.1302/0301-620X.92B11.24326.

9. Stiller CA, Craft AW, Corazziari I, EUROCARE Working Group. Survival of children with bone sarcoma in Europe since. Results from the EUROCARE study. Eur J Cancer. 1978;2001(37):760-6.

10. Kager L, Zoubek A, Dominikus M, Lang S, Bodmer N, Jundt G, Klingebiel T, Jürgens H, Gadner H, Bielack S. COSS study group. Osteosarcoma in very young children: experience of the cooperative osteosarcoma study group. Cancer. 2010;116(22):5316-24.

11. Malhas AM, Grimer RJ, Abudu A, Carter SR, Tillman RM, Jeys L. The final diagnosis in patients with a suspected primary malignancy of bone. J Bone Joint Surg Br. 2011;93:980-3.

12. Hauben El, Hogendoorn PCW. Epidemiology of primary bone tumors and economical aspects of bone metastases. In: Heymann D, editor. Bone cancer: progression and therapeutic approaches. 1st ed. London: Academic Press; 2009. p. 3-8.

13. Whelan JS, Jinks RC, McTiernan A, Sydes MR, Hook JM, Trani L, Uscinska B, Bramwell V, Lewis IJ, Nooij MA, et al. Survival from high-grade localised extremity osteosarcoma: combined results and prognostic factors from three European Osteosarcoma Intergroup randomised trials. Ann Oncol. 2012;23:1607-16.

14. Fletcher CD, Bridge JA, Hogendoorn P, Mertens F, editors. WHO classification of tumours of soft tissue and bone. 4th ed. Lyon: France IARC Press; 2013.

15. Eyre R, Feltbower RG, Mubwandarikwa E, Eden TO, McNally RJ. Review: epidemiology of bone tumours in children and young adults. Pediat Blood Cancer. 2009;53:941-52.

16. Kalra S, Grimer RJ, Spooner D, Carter SR, Tillman RM, Abudu A. Radiation induced sarcomas of bone. Factors that affect outcome. J Bone Joint Surg Br. 2007;89B:808-13.

17. SEER. http://seer.cancer.gov/statfacts/html/bones.html. Accessed 29 May 2015.

18. Dorfman HD, Czerniak B. Bone Cancers. Cancer. 1995;75:203-10.

19. Mascarenhas L, Siegel S, Spector L, Arndt C, Femino D, Malogolowkin M. Malignant bone tumours. SEER AYA Monograph, Chapter 8. 2002. p. 97-109.

20. Fuchs B, Pritchard DJ. Etiology of osteosarcoma. Clinical Orthop Rel Res. 2002;397:40-52.

21. Hansen MF, Seton M, Merchant A. Osteosarcoma in Paget's disease of bone. J Bone Min Res. 2006;21(Suppl 2):58-63.

22. Specht K, Sung YS, Zhang L, Richter GHS, Fletcher CD, Antonescu CR. Distinct transcriptional signature and immunoprofile of CIC-DUX4fusion positive round cell tumors compared to EWSR1-rearranged Ewing sarcomas-further evidence toward distinct pathological entities. Genes Chromosome Cancer. 2014;53(7):622-33.

23. Bernstein $M$, Kovar $H$, Paulussen M, Randall RL, Schuck A, Teot LA, Jüergens $H$. Ewing's sarcoma family of tumors: current management. Oncologist. 2006;11:503-19.

24. Paulussen M, Bielack S, Jürgens H, Casali PG, ESMO Guidelines Working Group. Ewing's sarcoma of the bone: ESMO clinical recommendations for diagnosis, treatment and follow-up. Ann Oncol. 2009;20(4):140-2.

25. Francis M, Dennis N, Charman J, Lawrence G, Grimer R. Bone and Soft Tissue Sarcomas UK Incidence and Survival: 1996 to 2010 November 2013 Version 2.0 NCIN. http://www.ncin.org.uk/publications/reports/. Accessed 29 May 2015. 
26. Lai X, Chen S. Identification of novel biomarker candidates for immunohistochemical diagnosis to distinguish low-grade chondrosarcoma from echondroma. Proteonomic. 2015;15(13):2358-68. doi:10.1002/ pmic.201400528 (Epub 2015 Apr 24).

27. Verdegaal SH, Bovee JV, Pansuriya TC, Grimer RJ, Ozger H, Jutte PC, San Julian M, Biau DJ, van der Geest IC, Leithner A, et al. Incidence, predictive factors and prognosis of chondrosarcoma in patients with Ollier Disease and Maffucci Syndrome: an International Multicenter Study of 161 patients. Oncologist. 2011;16:1771-9.

28. Eefting D, Schrage YM, Geirnaerdt MJ, Le Cessie S, Taminiau AH, Bovée $\mathrm{JV}$, Hogendoorn PC. EuroBoNeT consortium. Assessment of interobserver variability and histologic parameters to improve reliability in classification and grading of central cartilaginous tumors. Am J Surg Pathol. 2009;33:50-7.

29. Gelderblom H, Hogendoorn PCW, Dijkstra SD, van Rijswijk CS, Krol AD, Taminiau AH, Bovée JV. The clinical approach towards chondrosarcoma. Oncologist. 2008;13:320-9.

30. Riedel RF, Larrier N, Dodd L, Kirsch D, Martinez S, Brigman BE. The clinical management of chondrosarcoma. Curr Treat Options Oncol. 2009;10:94-106.

31. Grimer RJ, Gosheger G, Taminiau A, Biau D, Matejovsky Z, Kollender Y, San-Julian M, Gherlinzoni F, Ferrari C. Dedifferentiated chondrosarcoma: prognostic factors and outcome from a European group. Eur J Cancer. 2007:43:2060-5.

32. Romeo S, Bovee JV, Kroon HM, Tirabosco R, Natali C, Zanatta L, Sciot R, Mertens F, Athanasou N, Alberghini M, et al. Malignant fibrous histiocytoma and fibrosarcoma of bone: a reassessment in the light of currently employed morphological, immunochemical and molecular approaches. Virchows Arch. 2012;461:561-70.

33. Doyle LA. Sarcoma classification: an update based on the 2013 World Health Organization classification of tumors of soft tissue and bone. Cancer. 2014;120:1763-74.

34. Jeon DG, Song WS, Kong CB, Kim JR, Lee SY. MFH of bone and osteosarcoma show similar survival and chemosensitivity. Clin Orthop Rel Res. 2011:469:584-90.

35. Stacchiotti S. Sommer J on behalf of a chordoma global consensus group: a position paper from the medical and patient community. Lancet Oncol. 2015;16(2):e71-83.

36. Giannoulis DK, Gantsos A, Giotis D, Paschos NK, Vagionas A, Arnaoutoglou CM, Pentheroudakis G, Xenakis TA. Multiple recurrences and late metastasis of adamantinoma in the tibia: a case report. J Orthop Surg. 2014;22(3):420-2.

37. Roque P, Mankin HJ, Rosenberg A. Adamantinoma: an unusual bone tumour. Chir Organi Mov. 2008;92(3):149-54.

38. Viswanathan S, Jambhekar NA. Metastatic giant cell tumor of bone: are there associated factors and best treatment modalities? Clin Orthop Rel Res. 2010;468(3):827-33.

39. Bergovec M, Kubat O, Smerdelj M, Seiwerth S, Bonevski A, Orlic D. Epidemiology of musculoskeletal tumors in a national referral orthopedic department A study of 3482 cases. Cancer Epidemiol. 2015;39(3):298302. doi:10.1016/j.canep.2015.01.015 (Epub Feb 18 2015).

40. Campanacci M, Giunti A, Olmi R. Metaphyseal and diaphyseal localization of giant cell tumors. Chir Organi Mov. 1975;62(1):29-34.

41. Pakos EE, Grimer RJ, Peake D, Spooner D, Carter SR, Tillman RM, Abudu S, Jeys L. The other bone sarcomas: prognostic factors and outcomes for spindle cell sarcomas of bone. J Bone Joint Surg Br. 2011;93(9):1271-8.

42. Whelan JS, Pollock RC, Cassoni M, Windsor RE. Primary bone tumours. In: Price P, Sikora K, editors. Treatment of cancer. 6th ed. Boca Raton: CRC Press; 2014.

43. Grimer RJ, Sneath RS. Diagnosing malignant bone tumours. J Bone Joint Surg Br. 1990;72B:754-6.

44. Pizzo PA, Poplack DG. Osteosarcoma: principles and practice of pediatric oncology, 5th edn. 2006;35:1074-115.

45. Bielack SS, Machatschek JN, Flege S, Jürgens H. Delaying surgery with chemotherapy for osteosarcoma of the extremities. Exp Opin Pharmacother. 2004;5:1243-56.

46. Federman N, Bernthal N, Eilber FC, Tap WD. The multidisciplinary management of osteosarcoma. Curr Treat Opt Oncol. 2009;10:82-93.

47. National Institute for Health and Care Excellence (NICE). Guidance on cancer services -improving outcomes for people with sarcoma: the manual [needs assessment, evidence review, list of recommendations]; 2006. (Developed by the National Collaborating Centre for Cancer).

48. National Institute for Health and Care Excellence (NICE) Quality Standard QS55 Young People with Cancer; 2014. http://www.nice.org.uk/ guidance/qs55/resources/guidance-children-and-young-people-withcancer-pdf. Accessed 10 Jan 2016.

49. Mankin HJ, Lange TA, Spanier SS. The hazards of biopsy in patients with malignant primary bone and soft-tissue tumors. J Bone Joint Surg Ser A. 1982;64(8):1121-7.

50. Andreou D, Bielack DD, Carrle D, Kevric M, Kotz R, Winkelmann W, Jundt $G$, Werner M, Fehlberg S, Kager L, et al. The influence of tumor- and treatment-related factors on the development of local recurrence in osteosarcoma after adequate surgery. An analysis of 1335 patients treated on neoadjuvant Cooperative Osteosarcoma Group protocols. Ann Oncol. 2011;22:1228-35.

51. Healthcare Improvement Scotland. http://www.healthcareimprovementscotland.org/our_work/cancer_care_improvement/programme_ resources/scottish_referral_guidelines.aspx. Accessed 29 Feb 2016.

52. West of Scotland Cancer Network www.woscan.scot.nhs.uk. Accessed 29 Feb 2016.

53. Meyer JS, Nadel HR, Marina N, Womer RB, Brown KL, Eary JF, Gorlick R, Grier HE, Randall RL, Lawlor ER, et al. Imaging guidelines for children with Ewing sarcoma and osteosarcoma: a report from the Children's Oncology Group Bone Tumor Committee. Pediat Blood Cancer. 2008;51:163-70.

54. Picci P, Vanel D, Briccoli A, Talle K, Haakenaasen U, Malaguti C, Monti C, Ferrari C, Bacci G, Saeter G, et al. Computed tomography of pulmonary metastases from osteosarcoma: the less poor technique. A study of 51 patients with histological correlation. Ann Oncol. 2001;12:1601-4.

55. Wang S, Shi H, Yu Q. Osteosarcoma of the jaws: demographic and CT imaging features. Dentomaxillofacial Radiol. 2012;41:37-42.

56. Benz MR, Tchekmedyian N, Eilber FC, Federman N, Czernin J, Tap WD. Utilization of positron emission tomography in the management of patients with sarcoma. Curr Opin Oncol. 2009;21:345-51.

57. Newman EN, Jones RL, Hawkins DS. An evaluation of [F-18]-fluorodeoxy-D-glucose positron emission tomography, bone scan, and bone marrow aspiration/biopsy as staging investigations in Ewing sarcoma. Pediatr Blood Cancer. 2013;60(7):1113-7.

58. Quartuccio N, Fox J, Kuk D, Wexler LH, Baldari S, Cistaro A, Schöder H. Pediatric bone sarcoma: diagnostic performance of ${ }^{(18)}$ F-FDG PET/CT versus conventional imaging for initial staging and follow-up. Am J Roentgenol. 2015;204(1):153-60.

59. Bajpai J, Gamnagatti S, Kumar R, Sreenivas V, Sharma MC, Khan SA, Rastogi S, Malhotra A, Safaya R, Bakhshi S. Role of MRI in osteosarcoma for evaluation and prediction of chemotherapy response: correlation with histological necrosis. Pediatr Radiol. 2011;41:441-50.

60. Enneking WF, Spanier SS, Goodman MA. A system for the surgical staging of musculoskeletal sarcoma. Clin Orthop. 1980;53:106-20.

61. Edge SB, Byrd DR, Compton CC, Fritz AG, Greene FL, Trotti A (Eds.) AJCC Cancer Staging Manual, 7th edn. New York, NY: Springer 2010.

62. Bramer JA, van Linge JH, Grimer RJ, Scholten RJ. Prognostic factors in localized extremity osteosarcoma: a systematic review. Eur J Surg Oncol. 2009;35:1030-6.

63. Leavey PJ, Collier AB. Ewing sarcoma: prognostic criteria, outcomes and future treatment. Exp Rev Anticancer Ther. 2008;8:617-24.

64. Carrle D, Bielack SS. Current strategies of chemotherapy in osteosarcoma. Int Orthop. 2006;30:445-51.

65. Altuntas AO, Slavin J, Smith PJ, Schlict SM, Powell GJ, Ngan S, Toner G, Choong PF. Accuracy of computed tomography guided core needle biopsy of musculoskeletal tumours. ANZ J Surg. 2005;75:187-91.

66. Pramesh CS, Deshpande MS, Pardiwala DN, Agarwal MG, Puri A. Core needle biopsy for bone tumours. Eur J Surg Oncol. 2001;27:668-71.

67. Royal College of Pathologists Standards and datasets for reporting cancers: dataset for histopathology reports on primary bone tumours. February 2015. www.rcpath.org. Accessed 24 Feb 2015.

68. SNOMED CT. The language of the NHS Care Records Service www connectingforhealth.nhs.uk/publications 3769 (revised November 07). Accessed 24/02/215.

69. Machado I, Noguera R, Pellin A, Lopez-Guerrero JA, Piqueras M, Navarro S, Llombart-Bosch A. Molecular diagnosis of Ewing sarcoma family of 
tumors: a comparative analysis of 560 cases with FISH and RT-PCR. Diag Mol Pathol. 2009;18:189-99.

70. UK Clinical Research Network Study Portfolio. http://public.ukcrn.org. uk/search/. Accessed 29 Feb 2016.

71. National Cancer Research Institute Clinical Studies Groups. http://csg. ncri.org.uk/portfolio/portfolio-maps/ Accessed 29 Feb 2016.

72. Burgert EO, Nesbit ME, Garnsey LA, Gehan EA, Herrmann J, Vietti TJ, Cangir A, Tefft M, Evans R, Thomas P. Multimodal therapy for the management of nonpelvic, localized Ewing's sarcoma of bone: intergroup study IESS-II. J Clin Oncol. 1990;8:1514-24.

73. Anninga JK, Gelderblom H, Fiocco M, Kroep JR, Taminiau AH, Hogendoorn PC, Egeler RM. Chemotherapeutic adjuvant treatment for osteosarcoma: where do we stand? Eur J Cancer. 2011;16:2431-45.

74. Delaney T, Liebsch NJ, Pedlow FX, Adams J, Dean S, Yeap BY, McManus P, Rosenberg AE, Nielsen GP, Harmon DC, et al. Phase II study of high-dose photon/proton radiotherapy in the management of spine sarcomas. Int J Radiat Oncol Biol Phys. 2009;74(3):732-9.

75. Chen Y, Ciernik F, Niemierko A, Kobayashi, Y. Torunn, D. Ebb, D. Harmon, K. Raskin, and others. Treatment of unresectable osteosarcoma with proton therapy. Int J Radiat Oncol. 2009; 75(3).(Abst 2770).

76. Blattmann C, Oertel S, Schulz-Ertner D, Rieken S, Haufe S, Ewerbeck V, Unterberg A, Karapanagiotou-Schenkel I, Combs SE, Nikoghosyan A, et al. Non-randomized therapy trial to determine the safety and efficacy of heavy ion radiotherapy in patients with non-resectable osteosarcoma. BMC Cancer. 2010;10:96. doi:10.1186/1471-2407-10-96.

77. Noël G, Feuvret L, Ferrand R, Boisserie G, Mazeron JJ, Habrand JL. Radiotherapeutic factors in the management of cervical-basal chordomas and chondrosarcomas. Neurosurgery. 2004,55:1252-60.

78. Ares C, Hug EB, Lomax AJ, Bolsi A, Timmermann B, Rutz HP, Schuller JC, Pedroni E, Goitein G. Effectiveness and safety of spot scanning proton radiation therapy for chordomas and chondrosarcomas of the skull base: first long-term result. Int J Radiat Oncol Biol Phys. 2009;75(4):1111-8.

79. Yasuda M, Bresson D, Chibbaro S, Cornelius JF, Polivka M, Feuvret L, Takayasu M, George B, et al. Chordomas of the skull base and cervical spine: clinical outcomes associated with a multimodal surgical resection combined with proton-beam radiation in 40 patients. Neurosurg Rev. 2012;35(2):171-82.

80. Ciernik IF, Niemierko A, Harmon DC, Kobayashi W, Chen YL, Yock TI, Ebb DH, Choy E, Raskin KA, Liebsch N, et al. Proton-based radiotherapy for unresectable or incompletely resected osteosarcoma. Cancer. 2011;117(19):4522-30.

81. Imai R, Kamada T, Sugahara S, Tsuji H, Tsujii H. Br J Radiol. 2011;84(1):4854. doi:10.1259/bjr/13783281 (Epub 2011 Mar 22)

82. Staab Al, Rutz HP, Ares C, Timmermann B, Schneider R, Bolsi A, Albertini F, Lomax A, Goitein G, Hug E. Spot-scanning-based proton therapy for extracranial chordoma. Int J Radiat Oncol Biol Phys. 2011;81(4):489-96. doi:10.1016/j.jprobp.2011.02.018 (Epub 15 Apr 2011).

83. NHS Commissioning website. http://www.england.nhs.uk/commissioning/spec-services/npc-crg/group-b/b01/. Accessed 29 Feb 2016.

84. Salunke AA, Chen Y, Tan JH, Chen X, Khin LW, Puhaindran ME. Does pathological fracture affect the prognosis in patients with osteosarcoma of the extremities? a systematic review and meta-analysis. Bone Joint J. 2014;96:1396-403.

85. Xie C, Guo W, Li Y, Sun X. Pathological fracture does not influence local recurrence and survival in high-grade extremity osteosarcoma with adequate surgical margins. J Surg Oncol. 2012;106(7):820-5.

86. Reddy KI, Wafa H, Gaston CL, Grimer RJ, Abudu AT, Jeys LM, Carter $\mathrm{SR}$, Tillman RM. Does amputation offer any survival benefit over limb salvage in osteosarcoma patients with poor chemonecrosis and close margins? Bone Joint J. 2015;97(1):115-20.

87. Bramer JA, Abudu AA, Grimer RJ, Carter SR, Tillman RM. Do pathological fractures influence survival and local recurrence rate in bony sarcomas? Eur J Cancer. 2007:43(13):1944-51.

88. Carrle D, Bielack S. Osteosarcoma lung metastases detection and principles of multimodal therapy. In: Jaffe et al, editor. Pediatric and Adolescent Osteosarcoma: Cancer Treatment and Research, 152. DOI 10.1007/978-1-4419-0284-9_8. Springer Science+Business Media, LLC 2009.

89. Bacci G, Ferrari S, Bertoni F, Rimondini S, Longhi A, Bacchini P, Forni C, Manfrini M, Donati D, Picci P. Prognostic factors in nonmetastatic
Ewing's sarcoma of bone treated with adjuvant chemotherapy: analysis of 359 patients at the Istituto Ortopedico Rizzoli. J Clin Oncol. 2000;18:4-11.

90. Altaf S, Enders F, Jeavons E, Krailo M, Barkauskas DA, Meyers P, Arndt C. High BMl at diagnosis is associated with inferior survival in patients with osteosarcoma: a report from the Children's Oncology Group. Pediatr Blood Cancer. 2013;60(12):2042-6.

91. Collins M, Wilhelm M, Conyers R, Herschtal A, Whelan J, Bielack S, Kager L, Kühne T, Sydes M, Gelderblom H, et al. Benefits and adverse events in younger versus older patients receiving neoadjuvant chemotherapy for osteosarcoma: findings from a meta-analysis. J Clin Oncol. 2013;31:2310-2.

92. Janeway KA, Barkauskas DA, Krailo MD, Meyers PA, Schwartz CL, Ebb DH, Seibel NL, Grier HE, Gorlick R, Marina N. Outcome for adolescent and young adult patients with osteosarcoma. Cancer. 2012;118(18):4579-605.

93. Bielack S, Carrle D, Casali PG. ESMO Guidelines Working Group. Osteosarcoma: ESMO clinical recommendations for diagnosis, treatment and follow-up. Ann Oncol. 2009;20(4):137-9.

94. Grimer RJ. Surgical options for children with osteosarcoma. Lancet Oncol. 2005:6(2):85-92.

95. Lewis IJ, Nooij MA, Whelan J, Sydes MR, Grimer R, Hogendoorn PC, Memon MA, Weeden S, Uscinska BM, van Glabbeke M, et al. The MRC BO06 and EORTC 80931 collaborators and European osteosarcoma intergroup: improvement in histologic response but not survival in osteosarcoma patients treated with intensified chemotherapy: a randomized phase III trial of the European osteosarcoma intergroup. J Natl Cancer Inst. 2007;99:112-28.

96. Grimer RJ, Cannon SR, Taminiau AM, Bielack S, Kempf-Bielack B, Windhager R, Dominkus M, Saeter G, Bauer H, Meller I, et al. Osteosarcoma over the age of forty. Eur J Cancer. 2003;39:157-63.

97. Goorin AM, Schwartzentruber DJ, Devidas M, Gebhardt MC, Ayala AG, Harris MB, Helman $\sqcup$, Grier HE, Link MP, Pediatric Oncology Group. Presurgical chemotherapy compared with immediate surgery and adjuvant chemotherapy for nonmetastatic osteosarcoma: Pediatric Oncology Group Study POG-8651. J Clin Oncol. 2003;21:1574-80.

98. London and South East Sarcoma Network. Sarcoma guidelines. http:// www.Isesn.nhs.uk/guidelines.html. Accessed 31 Jan 2014.

99. Daw NC, Neel MD, Rao BN, Billups CA, Wu J, Jenkins JJ, Quintana J, Luchtman-Jones L, Villarroel M, Santana VM. Frontline treatment of localized osteosarcoma without methotrexate: results of the St Jude Children's Research Hospital OS99 trail. Cancer. 2011;117(12):2770-8.

100. Picci P, Sangiorgi L, Rougraff BT, Neff JR, Casadei R, Campanacci M. Relationship of chemotherapy-induced necrosis and surgical margins to local recurrence in osteosarcoma. J Clin Oncol. 1994;12:2699-705.

101. Meyers PA, Schwartz CL, Krailo MD, Healey JH, Bernstein ML, Betcher D, Ferguson WS, Gebhardt MC, Goorin AM, Harris M, et al. Children's Oncology Group. Osteosarcoma: the addition of muramyl tripeptide to chemotherapy improves overall survival-a report from the Children's Oncology Group. J Clin Oncol. 2008;26:633-8.

102. Goorin AM, Harris MB, Bernstein M, Ferguson W, Devidas M, Siegal GP, Gebhardt MC, Schwartz CL, Link M, Grier HE. Phase II/III trial of etoposide and high-dose ifosfamide in newly diagnosed metastatic osteosarcoma: a Pediatric Oncology Group trial. J Clin Oncol. 2002;20(2):426-33 (Epub 2002/01/12).

103. Navid F, Willert JR, McCarville MB, Furman W, Watkins A, Roberts W, Daw NC. Combination of gemcitabine and docetaxel in the treatment of children and young adults with refractory bone sarcoma. Cancer. 2008;113(2):419-25.

104. Eiber F, Guiliano A, Eckhardt J, Patterson K, Moseley S, Goodnight J. Adjuvant chemotherapy for osteosarcoma: a randomized prospective trial. J Clin Oncol. 1987;5:21-6.

105. Bernthal NM, Federman N, Eilber FR, Nelson SD, Eckardt JJ, Eilber FC, Tap WD. Long-term results ( $>25$ years) of a randomized, prospective clinical trial evaluating chemotherapy ion patients with high-grade, operable osteosarcoma. Cancer. 2012;118:5888-93.

106. van Dalen EC, van As JW, de Camargo B. Methotrexate for high-grade osteosarcoma in children and young adults Review. London: Wiley; 2009. http://onlinelibrary.wiley.com/doi/10.1002/14651858.CD006325. pub3/full. Accessed 20 Jan 2016. 
107. Whelan J, Patterson D, Perisoglou M, Bielack S, Marina N, Smeland S, Bernstein $\mathrm{M}$. The role of interferons in the treatment of osteosarcoma. Pediatr Blood Cancer. 2010;54(3):350-4. doi:10.1002/pbc.22136.

108. Whelan J, Bielack SS, Marina N, Smeland S, Jovic G, Hook JM, Krailo $M$, Anninga J, Butterfass-Bahloul T, Böhling T, et al. EURAMOS collaborators. EURAMOS-1, an international randomised study for osteosarcoma: results from pre-randomisation treatment. Ann Oncol. 2015;26:407-14.

109. Bielack SS, Smeland S, Whelan JS, Marina N, Jovic G, Hook JM, Krailo MD, Gebhardt M, Pápai Z, Meyer J, et al. EURAMOS-1 investigators. Methotrexate, doxorubicin, and cisplatin (MAP) plus maintenance pegylated interferon alfa- $2 \mathrm{~b}$ versus MAP alone in patients with resectable high-grade osteosarcoma and good histologic response to preoperative MAP: first results of the EURAMOS-1 Good Response Randomized Controlled Trial. J Clin Oncol. 2015;33(20):2279-87. doi:10.1200/ JCO.2014.60.0734

110. Bielack SS, Kempf-Bielack B, Delling G, Exner GU, Flege S, Helmke K, Kotz R, Salzer-Kuntschik M, Werner M, Winkelmann W, et al. For the cooperative German-Austrian-Swiss osteosarcoma group. Prognostic factors in high grade osteosarcoma of the extremities or trunk: an analysis of 1,702 patients treated on neoadjuvant cooperative osteosarcoma study group protocols. J Clin Oncol. 2002;20:776-90.

111. Byun BH, Kong CB, Lim I, Kim BI, Choi CW, Song WS, Cho WH, Jeon DG, Koh JS, Lee SY, et al. Early response monitoring to neoadjuvant chemotherapy in osteosarcoma using sequential 18 F-FDG PET/CT and MRI. Eur J Nucl Med Mol Imag. 2013;41:1553-62.

112. Wang CS, Du LJ, Si MJ, Yin QH, Chen L, Shu M, Yuan F, Fei XC, Ding XY. Noninvasive assessment of response to neoaduvant chemotherapy in osteosarcoma of long bones with diffusion-weighted imaging: an initial in vivo study. PLoS One. 2013;8(8):e72679.

113. National Institute for Health and Care Excellence (NICE) Neutropenic sepsis: prevention and management of neutropenic sepsis in cancer patients. NICE Guidelines [CG151]; 2012. http://www.nice.org.uk/guidance/cg151. Accessed 02 Feb 2015.

114. Frezza AM, Beale T, Bomanji J, Jay A, Kalavrezos N, Dileo P, Whelan J, Strauss SJ. Is [F-18]-fluorodeoxy-D-glucose positron emission tomography of value in the management of patients with craniofacial bone sarcomas undergoing neo-adjuvant treatment? BMC Cancer. 2014;14:23-9.

115. Kager $L$, Zoubek A, Potschger U, Kastner U, Flege S, Kempf-Bielack B, Branscheid D, Kotz R, Salzer-Kuntschik M, Winkelmann W, et al. Cooperative German-Austrian-Swiss Osteosarcoma Study Group. Primary metastatic osteosarcoma: presentation and outcome of patients treated on neoadjuvant Cooperative Osteosarcoma Study Group protocols. J Clin Oncol. 2003;21:2011-8.

116. Gelderblom H, Jinks RC, Sydes M, Bramwell VH, van Glabbeke M, Grimer RJ, Hogendoorn PC, McTiernan A, Lewis IJ, Nooij MA, et al. European Osteosarcoma Intergroup. Survival after recurrent osteosarcoma: data from 3 European Osteosarcoma Intergroup (EOI) randomized controlled trials. Eur J Cancer. 2011;47(6):895-902.

117. Garcia Franco CE. Torre W, Tamura A, Guillén-Grima F, San-Julian M, Martin-Algarra S, Pardo FJ. Long-term results after resection for bone sarcoma pulmonary metastases. Eur J Cardiothorac Surg. 2010;37:1205-8.

118. Ferrari S, Briccoli A, Mercuri M, Bertoni F, Picci P, Tienghi A, Del Prever AB, Fagioli F, Comandone A, Bacci G. Postrelapse survival in osteosarcoma of the extremities: prognostic factors for long-term survival. J Clin Oncol. 2003;21:710-5.

119. Kempf-Bielack B, Bielack SS, Juergens H, Branscheid D, Berdel WE, Exner GU, Göbel U, Helmke K, Jundt G, Kabisch H, et al. Osteosarcoma relapse after combined modality therapy: an analysis of unselected patients in the cooperative osteosarcoma study group (COSS). J Clin Oncol. 2005;23(3):559-68.

120. Berger M, Grignani G, Ferrari S, Biasin E. Brach del Prever A, Aliberti S, Saglio F, Aglietta M, Fagioli F. Phase 2 trial of two courses of cyclophosphamide and etoposide for relapsed high risk osteosarcoma patients. Cancer. 2009;115:2980-7.

121. Munoz A, Alfaro J, Pardo N, García-Miguel P, Quintero V, Gros L, Melero C, Antuña MJ, Ocete G, de Las Heras J, et al. Long-term results of the Spanish protocol SO-95 for the treatment of non-metastatic high-grade osteosarcoma of the extremeties in children. Clin Translat Oncol. 2009;11:387-92.
122. Anderson PM, Subbiah V, Rohren E. Bone-seeking radiopharmaceuticals as targeted agents of osteosarcoma: samarium153-EDTMP and radium-223. Adv Exp Med Biol. 2014;804:291-304. doi:10.1007/978-3-319-04843-7_16.

123. Grignani G, Palmerini E, Ferraresi V, D'Ambrosio L, Bertulli R, Asaftei SD, Tamburini A, Pignochino Y, Sangiolo D, Marchesi E, et al. Italian Sarcoma Group. Sorafenib and everolimus for patients with unresectable high-grade osteosarcoma progressing after standard treatment: a non-randomised phase 2 clinical trial. Lancet Oncol. 2015;16(1):98-107.

124. Buddingh EP, Anninga JK, Versteegh MI, Taminiau AH, Egeler RM, van Rijswijk CS, Hogendoorn PC, Lankester AC, Gelderblom H. Prognostic factors in pulmonary metastasized high grade osteosarcoma. Paediat Blood Cancer. 2010;54:216-21.

125. He JP, Hao Y, Li M, Wang J, Guo FJ.Tumor-to-background ratio to predict response to chemotherapy of osteosarcoma better than standard uptake values. Orthop Surg. 2014;6(2):145-53.

126. Leavey PJ, Mascarenhas L, Marina N, Chen Z, Krailo M, Miser J, Brown K, Tarbell N, Bernstein ML, Granowetter L, et al. Children's Oncology Group. Prognostic factors for patients with Ewing sarcoma (EWS) at first recurrence following multi-modality therapy: a report from the Children's Oncology Group. Pediatr Blood Cancer. 2008;51:334-8.

127. Bacci G, Forni C, Longhi A, Ferrari S, Donati D, De Paolis M, Barbieri E, Pignotti E, Rosito P, Versari M. Long-term outcome for patients with non-metastatic Ewing's sarcoma treated with adjuvant and neoadjuvant chemotherapies. 402 patients treated at Rizzoli between 1972 and 1992. Eur J Cancer. 2004:40:73-83.

128. Paulussen M, Ahrens S, Craft AW, Dunst J, Fröhlich B, Jabar S, Rübe C, Winkelmann W, Wissing S, Zoubek A, Jürgens H. Ewing's tumors with primary lung metastases: survival analysis of 114 (European Intergroup) Cooperative Ewing's Sarcoma Studies patients. J Clin Oncol. 1998;16:3044-52.

129. Bacci G, Palmerini E, Staals EL, Longhi A, Barbieri E, Alberghini M, Ferrari S. Ewing's sarcoma family tumours of the humerus: outcome of patients treated with radiotherapy, surgery or surgery and adjuvant radiotherapy. Radiother Oncol. 2009;93:383-7.

130. Schuck A, Ahrens S, Paulussen M, Kuhlen M, Könemann S, Rübe C, Winkelmann W, Kotz R, Dunst J, Willich N, Jürgens H. Local therapy in localized Ewing tumors: results of 1058 patients treated in the CESS 81, CESS 86, and EICESS 92 trials. Int J Radiat Oncol Biol Phys. 2003;55:168-77.

131. EURO-E.W.I.N.G 99 treatment manual. http://www.cancer.gov/clinicaltri$\mathrm{als} / \mathrm{search} / \mathrm{view}$ ?cdrid $=68608 \&$ version=healthprofessional. Accessed 03 Feb 2015.

132. Nesbit ME, Gehan EA, Burgert EO Jr, Vietti TJ, Cangir A, Tefft M, Evans R, Thomas P, Askin FB, Kissane JM. Multimodal therapy for the management of primary, nonmetastatic Ewing's sarcoma of bone: a long-term follow-up of the first intergroup study. J Clin Oncol. 1990:8:1664-74.

133. Grier HE, Krailo MD, Tarbell NJ, Link MP, Fryer CJ, Pritchard DJ, Gebhardt MC, Dickman PS, Perlman EJ, Meyers PA, et al. Addition of ifosfamide and etoposide to standard chemotherapy for Ewing's sarcoma and primitive neuroectodermal tumor of bone. New Eng J Med. 2003;348:694-701.

134. Jürgens H, Exner U, Gadner H, Harms D, Michaelis J, Sauer R, Treuner J, Voûte T, Winkelmann W, Winkler K. Multidisciplinary treatment of primary Ewing's sarcoma of bone: a 6-year experience of a European cooperative trial. Cancer. 1988;61:23-32.

135. Paulussen M, Craft AW, Lewis I, Hackshaw A, Douglas C, Dunst J, Schuck A, Winkelmann W, Köhler G, Poremba C, et al. European Intergroup Cooperative Ewing's Sarcoma Study-92. Results of the EICESS-92 study: two randomized trials of Ewing's sarcoma treatment-cyclophosphamide compared with ifosfamide in standard-risk patients and assessment of benefit of etoposide added to standard treatment in high-risk patients. J Clin Oncol. 2008;26(27):4385-93.

136. Pinkerton CR, Bataillard A, Guillo S, Oberlin O, Fervers B, Philip T. Treatment strategies for metastatic Ewing's sarcoma. Eur J Cancer. 2001;37:1338-44.

137. Wagner LM, McAllister N, Goldsby RE, Rausen AR, McNall-Knapp RY, McCarville MB, Albritton K. Temozolomide and intravenous irinotecan for treatment of advanced Ewing sarcoma. Pediat Blood Cancer. 2007;48:132-9.

138. Burdach S, Meyer-Bahlburg A, Laws HJ, Haase R, van Kaik B, Metzner B, Wawer A, Finke R, Göbel U, Haerting J, et al. High-dose therapy for 
patients with primary multifocal and early relapsed Ewing's tumors: results of two consecutive regimens assessing the role of total-body irradiation. J Clin Oncol. 2003;21:3072-8.

139. Le Deley M-C, Paulussen M, Lewis I, Brennan B, Ranft A, Whelan J, Le Teuff G, Michon J, Ladenstein R, Marec-Brard P, et al. Cyclophosphamide compared with ifosfamide in consolidation treatment of standard-risk Ewing sarcoma: results of the Randomized Noninferiority EuroEWING99-R1 Trial. J Clin Oncol. 2014;32(23):2440-8.

140. Womer RB, West DC, Krailo MD, Dickman PS, Pawel BR, Grier HE, Marcus K, Sailer S, Healey JH, Dormans JP, et al. Randomized controlled trial of interval-compressed chemotherapy for the treatment of localized Ewing sarcoma: a report from the Children's Oncology Group. J Clin Oncol. 2012;30:4148-54.

141. Ferrari S, Sundby Hall K, Lutsch R, Tienghi A, Wiebe T, Fagioli F, Alvegard TA, Brach Del Prever A, Tamburini A, Alberghini M, et al. Nonmetastatic Ewing family tumours: high-dose chemotherapy with stem cell rescue on poor responder patients. Results of the Italian Sarcoma Group/Scandinavian Sarcoma Group III protocol. Ann Oncol. 2011;22(5):1221-7.

142. Juergens C, Weston C, Lewis I, Whelan J, Paulussen M, Oberlin O, Michon J, Zoubek A, Jürgens H, Craft A. Safety assessment of intensive induction with vincristine, ifosfamide, doxorubicin, and etoposide (VIDE) in the treatment of Ewing tumors in the EURO-E.W.I.N.G. 99 clinical trial. Pediat Blood Cancer. 2006;47(1):22-9.

143. Ladenstein R, Potschger U, Le Deley MC, Whelan J, Paulussen M, Oberlin $\mathrm{O}$, van den Berg H, Dirksen U, Hjorth L, Michon J, et al. Primary disseminated multifocal Ewing sarcoma: results of the Euro-EWING 99 trial. J Clin Oncol. 2010;28:3284-91.

144. Ferrari S, del Prever AB, Palmerini E, Staals E, Berta M, Balladelli A, Picci P, Fagioli F, Bacci G, Vanel D. Response to high-dose ifosfamide in patients with advanced/recurrent Ewing sarcoma. Pediatr Blood Cancer. 2009;52(5):581-4.

145. Saylors RL 3rd, Stine KC, Sullivan J, Kepner JL, Wall DA, Bernstein ML, Harris MB, Hayashi R. Vietti TJ; Pediatric Oncology Group. Cyclophosphamide plus topotecan in children with recurrent or refractory solid tumors: a Pediatric Oncology Group phase II study. J Clin Oncol. 2001;19(15):3463-9.

146. Casey DA, Wexler LH, Merchant MS, Chou AJ, Merola PR, Price AP, Meyers PA. Irinotecan and temozolomide for Ewing sarcoma: the Memorial Sloan-Kettering experience. Pediatr Blood Cancer. 2009;53(6):1029-34.

147. McTiernan A, Driver D, Michelagnoli MP, Kilby AM, Whelan JS. High dose chemotherapy with bone marrow or peripheral stem cell rescue is an effective treatment option for patients with relapsed or progressive Ewing's sarcoma family of tumours. Ann Oncol. 2006;17:1301-5.

148. Fox E, Patel S, Wathen JK, Schuetze S, Chawla S, Harmon D, Reinke D, Chugh R, Benjamin RS, Helman L. Phase II Study of sequential gemcitabine followed by docetaxel for recurrent Ewing sarcoma, osteosarcoma, or unresectable or locally recurrent chondrosarcoma: results of sarcoma alliance for research through collaboration study 003. Oncol. 2012;17(3):321. doi:10.1634/theoncologist.2010-0265 (Epub 23 Feb 2012).

149. Mora J, Cruz CO, Parareda A, de Torres C. Treatment of relapsed/refractory pediatric sarcomas with gemcitabine and docetaxel. J Pediatr Hematol Oncol. 2009;31(10):723-9.

150. Kebudi R, Gorgun O, Ayan I. Oral etoposide for recurrent/progressive sarcomas of childhood. Pediatr Blood Cancer. 2004:42(4):320-4.

151. Euro Ewing Consortium. http://www.euroewing.eu/clinical-trials/ ee2012-trial. Accessed 29/2/2016.

152. Indelicato DJ, Keole SR, Shahlaee AH, Shi W, Morris CG, Marcus RB Jr. Definitive radiotherapy for Ewing tumors of extremities and pelvis: long-term disease control, limb function, and treatment toxicity. Int J Radiat Oncol Biol Phys. 2008;72(3):871-7.

153. DuBois SG, Krailo MD, Gebhardt MC, Donaldson SS, Marcus KJ, Dormans J, Shamberger RC, Sailer S, Nicholas RW, Healey JH, et al. Comparative evaluation of local control strategies in localized Ewing sarcoma of bone: a report from the Children's Oncology Group. Cancer. 2015;121(3):467-75.

154. Patel S, Delaney T. Advanced-technology radiation therapy for bone sarcomas. Cancer Control. 2008;15(1):21-37.

155. Sterzing F, Stoiber EM, Nill S, Bauer H, Huber P, Debus J, Münter MW. Intensity modulated radiotherapy (IMRT) in the treatment of children and adolescents-a single institution's experience and a review of the literature. Radiat Oncol. 2009;4:37. doi:10.1186/1748-717X-4-37.

156. Mounessi FS, Lehrich P, Haverkamp U, Willich N, Bolling T, Eich HT. Pelvic Ewing sarcomas. Three-dimensional conformal vs. intensity-modulated radiotherapy. Strahlenther Onkol. 2013;189(4):308-14. doi:10.1007/ s00066-012-0304-z (Epub 2013 Feb 28).

157. Pérez-Muñoz I, Grimer RJ, Spooner D, Carter S, Tillman RRR, Abudu A, Jeys L. Use of tissue expander in pelvic Ewing's sarcoma treated with radiotherapy. Eur J Surg Oncol. 2014;40(2):197-201. doi:10.1016/j. ejso.2013.09.001.

158. Euro-Ewing Radiotherapy Guidelines, Chapter XVII. In: EUROpean Ewing tumour Working Initiative of National Groups Ewing Tumour Studies 1999. EE 99 Amended Version 14th February 2006. https://www. skion.nl/workspace/uploads/ee99_amended_treo_2006_02_14.pdf. Accessed 20 Jan 2016.

159. Bernstein ML, Devidas M, Lafreniere D, Souid AK, Meyers PA, Gebhardt M, Stine K, Nicholas R, Perlman EJ, Dubowy R, Pediatric Oncology Group, Children's Cancer Group Phase II Study 9457, Children's Oncology Group, et al. Intensive therapy with growth factor support for patients with Ewing tumor metastatic at diagnosis: Pediatric Oncology Group/Children's Cancer Group Phase II Study 9457-a report from the Children's Oncology Group. J Clin Oncol. 2006;24:152-9.

160. Whelan JS, Burcombe RJ, Janinis J, Baldelli AM, Cassoni AM. A systematic review of the role of pulmonary irradiation in the management of primary bone tumours. Ann Oncol. 2002;13:23-30.

161. Brown LC, Lester RA, Grams MP, Haddock MG, Olivier KR, Arndt CA, Rose PS, Laack NN. Stereotactic radiotherapy for metastatic and recurrent Ewing sarcoma and osteosarcoma. Sarcoma. 2014;418270:9. doi:10.1155/2014/418270.

162. Cotterill SJ, Ahrens S, Paulussen M, Jürgens HF, Voûte PA, Gadner H, Craft AW. Prognostic factors in Ewing's tumor of bone: analysis of 975 patients from the European Intergroup Cooperative Ewing's Sarcoma Study Group. J Clin Oncol. 2000;18:3108-14.

163. Cangir A, Vietti TJ, Gehan EA, Burgert EO Jr, Thomas P, Tefft M, Nesbit ME, Kissane J, Pritchard D. Ewing's sarcoma metastatic at diagnosis. Results and comparisons of two intergroup Ewing's sarcoma studies. Cancer. 1990;66:887-93.

164. McTiernan AM, Cassoni AM, Driver D, Michelagnoli MP, Kilby AM, Whelan JS. Improving outcomes after relapse in Ewing's Sarcoma: analysis of 114 patients from a single institution. Sarcoma. 2006;2006:1-8.

165. Stahl M, Ranft A, Paulussen M, Bölling T, Vieth V, Bielack S, Görtitz I, Braun-Munzinger $\mathrm{G}$, Hardes J, Jürgens $\mathrm{H}$, et al. Risk of recurrence and survival after relapse in patients with Ewing sarcoma. Pediatr Blood Cancer. 2011;57(4):549-53.

166. Abudu A, Davies AM, Pynsent PB, Mangham DC, Tillman RM, Carter SR, Grimer RJ. Tumour volume as a predictor of necrosis after chemotherapy in Ewing's sarcoma. J Bone Joint Surg Br. 1999;81(2):317-22.

167. Boriani S, Bandiera S, Biagini R, Bacchini P, Boriani L, Cappuccio M, Chevalley F, Gasbarrini A, Picci P, Weinstein JN. Chordoma of the mobile spine: 50 years of experience. Spine. 2006;31:493-503.

168. Xie L, Whalley N, Adasonia K, Grimer R, Jeys L. Can local recurrence of a sacral chordoma be treated by further surgery? Bone Joint J. 2015;97(5):711-5

169. Stacchiotti S, Marrari A, Tamborini E, Palassini E, Virdis E, Messina A, Crippa F, Morosi C, Gronchi A, Pilotti S, et al. Response to imatinib plus sirolimus in advanced chordoma. Ann Oncol. 2009;20:1886-94.

170. Stacchiotti S, Longhi A, Ferraresi V, Grignani G, Comandone A, Stupp R, Bertuzzi A, Tamborini E, Pilotti S, Messina A, et al. Phase II study of imatinib in advanced chordoma. J Clin Oncol. 2012;30(9):914-20.

171. Brewer P, Sumathi V, Grimer RJ, Carter SR, Tillman RM, Abudu A, Jeys L. Primary leiomyosarcoma of bone: analysis of prognosis. Sarcoma. 2012;636849:4. doi:10.1155/2012/636849.

172. National Cancer Institute (NCl). General information about osteosarcoma and malignant fibrous histiosarcoma (MFH) of bone. http://www. cancer.gov/cancertopics/types/bone. Accessed 02 Feb 2015.

173. Chawla S, Henshaw R, Seeger L, Choy E, Blay JY, Ferrari S, Kroep J, Grimer $R$, Reichardt P, Rutkowski P, et al. Safety and efficacy of denosumab for adults and skeletally mature adolescents with giant cell tumour of bone: interim analysis of an open-label, parallel-group, phase 2 study. Lancet Oncol. 2013;14(9):901-8. 
174. Rutkowski P, Ferrari S, Grimer RJ, Stalley PD, Dijkstra SP, Pienkowski A, Vaz G, Wunder JS, Seeger LL, Feng A, et al. Surgical downstaging in an open-label phase II trial of denosumab in patients with giant cell tumor of bone. Ann Surg Oncol. 2015;22(9):2860-8. doi:10.1245/ s10434-015-4634-9.

175. Thomas D, Henshaw R, Skubitz K, Chawla S, Staddon A, Blay JY, Roudier M, Smith J, Ye Z, Sohn W, et al. Denosumab in patients with giant-cell tumour of bone: an open-label, phase 2 study. Lancet Oncology. 2010;11(3):275-80.

176. Fleming GF, Heimann PS, Stephens JK, Simon MA, Ferguson MK, Benjamin RS, Samuels BL. Dedifferentiated chordoma. Response to aggressive chemotherapy in two cases. Cancer. 1993;72(3):714-8

\section{(Epub 1993/08/01)}

177. George S, Merriam P, Maki RG, Van den Abbeele AD, Yap JT, Akhurst T, Harmon DC, Bhuchar G, O'Mara MM, D'Adamo DR, et al. Multicenter phase II trial of sunitinib in the treatment of nongastrointestinal stromal tumor sarcomas. J Clin Oncol. 2009;27(19):3154-60.

178. Puri A, Gulia A, Hawaldar R, Ranganathan P, Badwe RA. Does intensity of surveillance affect survival after surgery for sarcomas? results of a randomized noninferiority trial. Clin Orthop Rel Res. 2014;472(5):1568-75.
179. Aksnes LH, Bauer HC, Dahl AA, Fosså SD, Hjorth L, Jebsen N, Lernedal $\mathrm{H}$, Hall KS. Health status at long-term follow up in patients treated for extremity localized Ewing sarcoma or osteosarcoma: a Scandinavian sarcoma group study. Pediatr Blood Cancer. 2009;53:84-9.

180. Langer T, Stöhr W, Paulides M, Kremers A, Dörr HG, Göbel U, Beck JD. Prospective multicenter registration of major late sequelae in sarcoma patients using the late effects surveillance system (LESS). Klinische Pädiatrie. 2005;217:176-81.

181. Bassal M, Mertens AC, Taylor L, Neglia JP, Greffe BS, Hammond S, Ronckers CM, Friedman DL, Stovall M, Yasui YY, et al. Risk of selected subsequent carcinomas in survivors of childhood cancer: a report from the childhood cancer survivor study. Clin Oncol. 2006;24(3):476-83.

182. Rodriguez-Galindo C, Poquette C, Marina NM, Head DR, Cain A, Meyer WH, Santana VM, Pappo AS. Hematologic abnormalities and acute myeloid leukemia in children and adolescents administered intensified chemotherapy for the Ewing sarcoma family of tumours. J Pediat Oncol. 2000:22(4):321-9.

\section{Submit your next manuscript to BioMed Central and we will help you at every step:}

- We accept pre-submission inquiries

- Our selector tool helps you to find the most relevant journal

- We provide round the clock customer support

- Convenient online submission

- Thorough peer review

- Inclusion in PubMed and all major indexing services

- Maximum visibility for your research

Submit your manuscript at www.biomedcentral.com/submit
() BioMed Central 